University of Nebraska - Lincoln

DigitalCommons@University of Nebraska - Lincoln

\title{
The effect of mineral-ion interactions on soil hydraulic conductivity
}

\author{
Maya C. Buelow \\ Department of Land, Air and Water Resources \\ Kerri Steenwerth \\ USDA-ARS Crops Pathology and Genetics Research Unit c/o Department of Viticulture and Enology \\ Sanjai J. Parikh \\ Department of Land, Air and Water Resources, sjparikh@ucdavis.edu
}

Follow this and additional works at: https://digitalcommons.unl.edu/usdaarsfacpub

Part of the Environmental Monitoring Commons

Buelow, Maya C.; Steenwerth, Kerri; and Parikh, Sanjai J., "The effect of mineral-ion interactions on soil hydraulic conductivity" (2015). Publications from USDA-ARS / UNL Faculty. 1497.

https://digitalcommons.unl.edu/usdaarsfacpub/1497

This Article is brought to you for free and open access by the U.S. Department of Agriculture: Agricultural Research Service, Lincoln, Nebraska at DigitalCommons@University of Nebraska - Lincoln. It has been accepted for inclusion in Publications from USDA-ARS / UNL Faculty by an authorized administrator of DigitalCommons@University of Nebraska - Lincoln. 


\title{
The effect of mineral-ion interactions on soil hydraulic conductivity
}

\author{
Maya C. Buelow ${ }^{\mathrm{a}}$, Kerri Steenwerth ${ }^{\mathrm{b}}$, Sanjai J. Parikh ${ }^{\mathrm{a}, *}$ \\ a Department of Land, Air and Water Resources, One Shields Ave., University of California Davis, Davis, CA 95616, USA \\ b USDA/ARS Crops Pathology and Genetics Research Unit, c/o Department of Viticulture and Enology, RMI North, Rm 1151, 595 Hilgard Ln., Davis, \\ CA 95616, USA
}

\section{A R T I C L E I N F O}

\section{Article history:}

Received 5 February 2014

Accepted 14 January 2015

Available online 20 February 2015

\section{Keywords:}

Mineralogy

Salinity

Winery

Wastewater reuse

Vineyard

Irrigation

\begin{abstract}
A B S T R A C T
The reuse of winery wastewater (WW) could provide an alternative water source for vineyard irrigation. The shift of many wineries and other food processing industries to $\mathrm{K}^{+}$-based cleaners requires studies on the effects of $\mathrm{K}^{+}$on soil hydraulic conductivity (HC). Depending on clay content and mineral composition, $\mathrm{K}^{+}$additions can affect the HC either positively or negatively. Soil mineralogy was anticipated to exhibit a strong influence on $\mathrm{HC}$ responses and, therefore, soils of contrasting mineralogy were evaluated for changes in soil $\mathrm{HC}$ resulting from applications of solutions elevated in $\mathrm{Na}^{+}$and $\mathrm{K}^{+}$. To examine the impact of mineral-ion relationships on HC, soils dominant in montmorillonite, vermiculite, or kaolinite from the Napa and Lodi wine regions of California, were packed into soil columns to observe changes in leachate chemistry and $\mathrm{HC}$. Irrigation with $\mathrm{Na}^{+}-$and $\mathrm{K}^{+}$-rich WW was simulated by applying solutions at sodium absorption ratio (SAR) values of 3, 6, and 9 and potassium absorption ratio (PAR) values of 1, 2, 4, and 9 . While HC was reduced in the 2:1 clay soils (montmorillonite and vermiculite) for all SAR treatments, the vermiculite and the kaolinite rich soils exhibited equal or greater reductions in HC for PAR treatments, as compared with the SAR treatments. Findings from this evaluation of the interaction of $\mathrm{Na}^{+}$and $\mathrm{K}^{+}$with three different mineral soils suggest that the reuse of WW with increasing PAR are least problematic for montmorillonite dominated soils and most detrimental to the HC of the vermiculite dominated soil. The presence of minerals with a high affinity for $\mathrm{K}^{+}$(e.g., vermiculite, mica) in this soil suggest that the interlayer binding of $\mathrm{K}^{+}$could lead to greater reductions in HC. Full analysis of soil and WW is recommended prior to all land applications.
\end{abstract}

(c) 2015 Elsevier B.V. All rights reserved.

\section{Introduction}

The reuse of wastewater is an attractive solution to address water scarcity. While the salt concentration of wastewater is typically moderate $\left(\sim 1.5 \mathrm{dS} \mathrm{m}^{-1}\right)$ and can be applied to land, applications of sodium $\left(\mathrm{Na}^{+}\right)$-rich water increase the risk of sodic conditions occurring in the soil profile, degrade soil quality, and limit productivity (Laurenson et al., 2012). The total salinity of irrigation water (measured as electrical conductivity in $\mathrm{dS} \mathrm{m}^{-1}$ or electrolyte concentration in $\mathrm{mEq} \mathrm{L}^{-1}$ ) can also influence the permeability of a soil and its hydraulic conductivity (HC) (Abusharar et al., 1987; Keren and Singer, 1989). The organic components of winery-wastewater (WW) are effectively reduced by most forms of treatment, whereas salts persist in the water after treatment. A companion study conducted in 2013, looking at California WW composition, revealed that the SAR and PAR of California WW

\footnotetext{
* Corresponding author. Tel.: +1 5307521265 .

E-mail address: sjparikh@ucdavis.edu (S.J. Parikh).
}

after on-site water treatment ranged from 1 to 9 (Buelow, 2013). Typically, WW has a salt composition dominated by $\mathrm{Na}^{+}$, but the adoption of potassium $\left(\mathrm{K}^{+}\right)$-based cleaners is shifting the composition of these waste streams. The impacts of $\mathrm{Na}^{+}$-rich water on soil physical and chemical properties and plant health have been studied and debated extensively (Arienzo et al., 2012; Benitez et al., 1999; Chen et al., 1983; Frenkel et al., 1978; Frenkel, 1985; Hamilton et al., 2007; Hermon et al., 2008; Jayawardane et al., 2011; Laurenson et al., 2012; Nightingale, 1959; Quirk and Schofield, 1955). However, $\mathrm{K}^{+}$is less well understood (Arienzo et al., 2012). Our recent WW survey in Northern California has shown that pre- and post-treatment concentrations of $\mathrm{K}^{+}$to range from 2$772 \mathrm{mg} \mathrm{L}^{-1}$, with a maximum PAR of 11.8 , and thus research is needed to examine how these wastewaters might impact vineyard production systems (Buelow, 2013).

Ubiquitous in wine industry cleaners, $\mathrm{Na}^{+}$and $\mathrm{K}^{+}$salts are not removed by typical or affordable WW treatment processes (Mosse et al., 2011), presenting a considerable hurdle to its reuse in agriculture. In order to assess the hazard posed by $\mathrm{Na}^{+}$to soil structure and HC, the sodium adsorption ratio (Eq. (1)-SAR), a weighted ratio 
of $\mathrm{Na}^{+}$to other divalent cations in solution, is used as the standard water quality measurement, where concentrations of cations are in $\mathrm{mEq} \mathrm{L^{-1 }}$ (Endo et al., 2002). A similar calculation exists for the potassium adsorption ratio (Eq. (2)PAR) (Chen et al., 1983). Equivalent equations for exchangeable ions of the soil surface are exchangeable sodium percentage (Eq. (3)-ESP) (Endo et al., 2002) and exchangeable potassium percentage (Eq. (4)-EPP) (Chen et al., 1983). Guidelines for interpretations of water quality for irrigation have shown SAR values from 3 to 9 to fall into the slight to moderate risk for reductions in infiltration at EC $>0.3-0.5$, and are severely hazardous if $\mathrm{EC}<0.3-0.5 \mathrm{dS} \mathrm{m}^{-1}$ (Ayers, 1985).

$\mathrm{SAR}=\frac{\mathrm{Na}^{+}}{\sqrt{1 / 2\left(\mathrm{Ca}^{2+}+\mathrm{Mg}^{2+}\right)}} \quad$ Concentrations in $\mathrm{mEq} \mathrm{L}^{-}$

$\mathrm{PAR}=\frac{\mathrm{K}^{+}}{\sqrt{1 / 2\left(\mathrm{Ca}^{2+}+\mathrm{Mg}^{2+}\right)}} \quad$ Concentrations in $\mathrm{mEq} \mathrm{L}^{-1}$

$\mathrm{ESP}=\frac{\mathrm{Na}^{+}}{\mathrm{Na}^{+}+\mathrm{K}^{+}+\mathrm{Mg}^{2+}+\mathrm{Ca}^{2+}}(100)$

Concentrations in mEq $100 \mathrm{~g} \mathrm{soil}^{-1}$

$$
\begin{aligned}
\mathrm{EPP}= & \frac{\mathrm{K}^{+}}{\mathrm{Na}^{+}+\mathrm{K}^{+}+\mathrm{Mg}^{2+}+\mathrm{Ca}^{2+}}(100) \\
& \text { Concentrations in mEq } 100 \mathrm{~g} \text { soil }^{-1}
\end{aligned}
$$

Clay mineralogy has also been shown to have a large influence on reductions in HC (Churchman et al., 1993; McNeal and Coleman, 1966). Smectites show extensive swelling and dispersion, due to their 2:1 layer structure, which accommodates a high amount of exchangeable $\mathrm{Na}^{+}$within its interlayer space (Arienzo et al., 2012; Churchman et al., 1993). $\mathrm{Na}^{+}$is a large monovalent ion and more effectively forces clay tactoids (i.e., particles) apart than $\mathrm{Ca}^{2+}$ or $\mathrm{Mg}^{2+}$ (Quirk, 1986). Swelling occurs with increasing $\mathrm{Na}^{+}$concentration, as hydration of $\mathrm{Na}^{+}$leads to the expansion of the interlayer $(E S P>15)$. Dispersive conditions are described as mutual repulsion of tactoids fully surrounded by associated $\mathrm{Na}^{+}$and waters of hydration (ESP < 15) Essington (2004). Smectitic soils usually disperse more in weak salt solution at low SAR values than do kaolinitic soils, as indicated by a more abrupt and larger decrease in HC (Frenkel et al., 1978; Keren and Singer, 1988). Soils high in kaolinite have been found to be quite stable, even when exposed to $3.13 \mathrm{mEq} \mathrm{L}^{-1}$ $\mathrm{NaCl}$ (McNeal and Coleman, 1966). Intermediate in their behavior are soils that contain primarily 2:1 layer silicates other than smectites, such as vermiculite or illite (McNeal and Coleman, 1966).

The diversity of the behavior of $\mathrm{K}^{+}$in soil has also been suggested as dependent on clay content, soil mineralogy, and possibly $\mathrm{K}^{+}-$ fixation (Jayawardane et al., 2011; Shainberg et al., 1980; Sumner, 1993). Solutions enriched in $\mathrm{K}^{+}$can improve soil HC, possibly through $\mathrm{Na}^{+}$displacement (Chen et al., 1983; Levy and Torrento, 1995; Ravina and Low, 1972; Ravina and Markus, 1975). However, additions of $\mathrm{K}^{+}$led to reductions in $\mathrm{HC}$ in an illite soil and a low cation exchange capacity (CEC) montmorillonite soil (Chen et al., 1983; Laurenson et al., 2011). In one study, the effect of exchangeable $\mathrm{K}^{+}$on permeability was examined in three soils, a loamy sand, a light clay, and a heavy clay, each containing close to $50 \%$ montmorillonite (Chen et al., 1983). Increases in EPP up to 20 did not destabilize the loamy sand or the heavy clay. In the light clay, which contained 16\% illite, any increase in EPP lead to a decrease in HC, likely due to illite binding additional $\mathrm{K}^{+}$(Chen et al., 1983). Similarly, the addition of $\mathrm{K}^{+}\left(3 \mathrm{mEq} \mathrm{L}{ }^{-1}\right)$ to irrigation water $\left(<60 \mathrm{mg} \mathrm{L}^{-1}\right.$ soluble salts) significantly reduced water infiltration in a vermiculitic San Joaquin sandy loam, as compared to an untreated control
(Peacock, 2007). The aforementioned soils, which contained $\mathrm{K}^{+}$fixing clays like vermiculite and illite, showed greater reductions in $\mathrm{HC}$ associated with high $\mathrm{K}^{+}$concentrations than in soils without $\mathrm{K}^{+}$-fixation.

Little published research exists specifically on WW reuse for irrigation of grapevines. In California there are examples of wineries reusing treated WW for landscaping and frost protection (Hamilton et al., 2007), and several case studies of wastewater characterization and treatment for reuse have been published, including research conducted in Australia (Christen et al., 2010; Laurenson et al., 2012), Spain (Bustamante et al., 2005), South Africa (Mulidzi, 2007), and Mexico (Mendoza-Espinosa et al., 2008). A recent study compared the effects of solutions, ranging in SAR and PAR from 5 to 40 , on a predominantly montmorillonite Australian vineyard soil (Arienzo et al., 2012). Treatment solutions combining either $\mathrm{Na}^{+}$or $\mathrm{K}^{+}$with $\mathrm{Ca}^{2+}, \mathrm{Mg}^{2+}$, or $\mathrm{Ca}^{2+}-\mathrm{Mg}^{2+}$ were applied to repacked soil columns, and the reductions in HC were found to be greater in magnitude for the $\mathrm{Na}^{+}$than for the $\mathrm{K}^{+}$solutions (Arienzo et al., 2012). The treatment solutions were applied to only one soil type, and it remains that the effects of reusing $\mathrm{K}^{+}$-rich WW on the HC of soils with contrasting mineralogy requires further investigation (Jayawardane et al., 2011).

As such, we present for the first time the effects of $\mathrm{Na}^{+}$and $\mathrm{K}^{+}$-rich solutions on the HC of three vineyard soils of contrasting mineralogy, dominant in montmorillonite, vermiculite, or kaolinite from Northern California, treated with aqueous salt concentrations that reflect conditions found in a WW survey of California wineries (Buelow, 2013). Selected soils represent common soil types supporting vineyard production in Northern California (O'Geen et al., 2008). Soil column studies were conducted to obtain HC measurements and reductions in $\mathrm{HC}$ were then used to compare the effects of saline solutions on water movement in three contrasting soils.

\section{Materials and methods}

\subsection{Soil sampling and preparation}

The three soil types chosen for this study are representative of Northern California vineyard soils with differing mineralogy. They included; (1) Bale fine loam from Napa (fine-loamy, mixed, superactive, thermic Cumulic Ultic Haploxeroll), (2) Redding gravelly loam from Lodi (fine, mixed, active, thermic Abruptic Durixeralf), and (3) San Joaquin loam from Lodi (fine, mixed, active, thermic Abruptic Durixeralf) (NRCS, 2011). Bale was the only soil containing montmorillonite, Redding contained predominantly kaolinite, and vermiculite was unique to San Joaquin (Table 1). The horizon of illuvial clay and salt accumulation (Bt1 horizon) was selected. This focused the study on the layer with highest clay content and most distinct representation of mineralogical characteristics for a given soil type. The intent was to focus on a soil horizon often impacted by salts under irrigated conditions; irrigated soils generally possess lower salinity at the surface and show increasing salinity with depth (Frenkel et al., 1978; Halliwell et al., 2001). Collected soils were air dried and sieved to isolate the $\leq 2 \mathrm{~mm}$ fraction.

\subsection{Soil characteristics}

Characteristics of the three soils: (1) Bale dominated by montmorillonite (Bale-mont), (2) Redding rich in kaolinite (Red-kao), and (3) San Joaquin dominant in vermiculite (SJ-ver) are provided in Table 1. Soil particle size distribution was determined on a mass basis by the pipette method (Burt and Staff, 2014), soil pH (Thermo Scientific Orion 4 Star meter; Fisher Scientific Accumet Gel-filled Pencil-Thin Epoxy Body pH Combination ElectrodesMercury-Free 13-620-252) and EC (Thermo Scientific Orion 4 Star 
Table 1

Soil characteristics for Bt1 horizon (horizon of illuvial clay and salt accumulation) samples used in soil column experiments.

\begin{tabular}{|c|c|c|c|c|}
\hline Location & Unit & Bale-mont & Red-kao & SJ-ver \\
\hline & & Napa & Lodi & Lodi \\
\hline \multirow[t]{2}{*}{ GPS coordinates } & & W 122.406957 & W 121.147179 & W 121.31847 \\
\hline & & N 38.471985 & N 38.284831 & N 38.19865 \\
\hline Horizon & - & Bt1 & Bt1 & Bt1 \\
\hline $\mathrm{pH}$ & - & 6.8 & 5.0 & 6.6 \\
\hline CEC & $\mathrm{mEq} 100 \mathrm{~g}^{-1}$ & 26.2 & 10.2 & 21.2 \\
\hline Activity & - & 1.3 & 0.3 & 0.7 \\
\hline $\mathrm{K}^{+}$ & $\mathrm{mEq} 100 \mathrm{~g}^{-1}$ & 0.65 & 0.71 & 0.40 \\
\hline K-fixation & $\mathrm{mg} \mathrm{kg}^{-1}$ & -78.27 & -170.61 & 12.32 \\
\hline $\mathrm{Na}^{+}$ & $\mathrm{mEq} 100 \mathrm{~g}^{-1}$ & 0.03 & 0.02 & 0.12 \\
\hline $\mathrm{Ca}^{2+}$ & $\mathrm{mEq} 100 \mathrm{~g}^{-1}$ & 17.05 & 1.93 & 9.16 \\
\hline $\mathrm{Mg}^{2+}$ & $\mathrm{mEq} 100 \mathrm{~g}^{-1}$ & 2.15 & 0.53 & 4.18 \\
\hline ESP & - & 0.11 & 0.20 & 0.57 \\
\hline EPP & - & 2.48 & 6.96 & 1.89 \\
\hline Sand & $\%$ & 47.7 & 35.6 & 36.1 \\
\hline Silt & $\%$ & 31.7 & 27.3 & 33.8 \\
\hline Clay & $\%$ & 19.7 & 36.6 & 28.7 \\
\hline OM & $\%$ & 0.9 & 0.5 & 1.4 \\
\hline Mineralogy ${ }^{*}$ & - & sM, M, K & $\mathrm{K}, \mathrm{M}$ & $\mathrm{V}, \mathrm{K}, \mathrm{M}$ \\
\hline
\end{tabular}

* sM-smectite-montmorillonite, $\mathrm{M}$-mica, $\mathrm{K}$-kaolinite, $\mathrm{V}$-vermiculite.

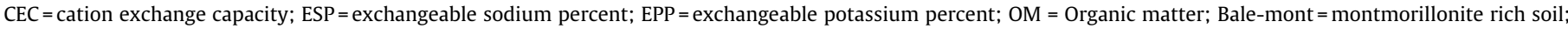
Red-kao = kaolinite rich soil; SJ-ver = vermiculite rich soil.

meter; DuraProbe ${ }^{\mathrm{TM}} 4013005 \mathrm{MD}$ conductivity cell) were measured from saturated paste extracts (Burt and Staff, 2014). The cation exchange capacity (CEC), base saturation, and ion concentrations were determined by the UC Davis College of Agriculture and Environmental Sciences Analytical Laboratory following standard methods (Rible, 1960). Clay mineral activity was calculated by dividing CEC ( $\mathrm{mEq} 100 \mathrm{~g}^{-1}$ ) by mass percentage of clay (Burt and Staff, 2014). Soil cation data was used to calculate ESP and EPP (Table 1). Gravimetric water content was measured using the ovendry method at $105^{\circ} \mathrm{C}(24 \mathrm{~h})$. $\mathrm{K}^{+}$-fixation potential was determined by standard methods and detailed in Murashkina et al. (2007). Mineralogical composition of the clay fraction was determined via X-ray diffraction (Murashkina et al., 2007).

\subsection{Soil hydraulic conductivity measurements}

Changes in $\mathrm{HC}$ in response to the application of SAR and PAR solutions were measured according to standard methods (Keren and Singer, 1988; Levy and Torrento, 1995; Shainberg et al., $1987)$. The prepared soils were packed into Plexiglas columns $(8.3 \mathrm{~cm}$ diam. $\times 5.0 \mathrm{~cm})$ to a target bulk density of approximately $1.35 \mathrm{~g} \mathrm{~cm}^{-3}$ ( $n=3$ columns per treatment). Treatment solutions were composed of $\mathrm{NaCl}$ - and $\mathrm{KCl}-\mathrm{CaCl}_{2}-\mathrm{MgCl}_{2}$ (for SAR values of 3, 6, and 9 and PAR values of 1,2, 4 and 9, respectively).The ratio of Ca:Mg was maintained at 2:1 (Shainberg, 1990). These values and ranges were selected to reflect realistic scenarios in vineyard systems where WW is applied. They were defined by values that were calculated from pre- and post-treatment WW samples from 18 California wineries that were collected monthly over 1.5 years (Buelow, 2013). The SAR or PAR of each leaching solution was held constant while the total salt concentration was progressively decreased $\left(50,25,12,6,0 \mathrm{mEq} \mathrm{L}^{-1}\right)$. For a given SAR or PAR value, the salt concentration at which clay disperses spontaneously, and HC has been reduced by $20 \%$, is defined as the threshold electrolyte concentration, $\mathrm{TE}_{\text {conc }}$ (Keren and Singer, 1988; Quirk, 2001; Rengasamy, 2002). Reduction in HC resulting from swelling and dispersion is often irreversible and occurs below the $\mathrm{TE}_{\text {conc }}$ (Levy and Torrento, 1995). This necessitates starting at a high salt concentration and incrementally reducing the salinity of the solution in HC column experiments.

Each treatment solution was applied to fresh soil columns and completed in triplicate to minimize variability between columns
( $n=3$ columns per treatment). After purging columns with $\mathrm{CO}_{2}$ for two hours to displace air and prevent the formation of air pockets, the soil was saturated from below via capillary action using the first solution in the series $\left(50 \mathrm{mEq} \mathrm{L}^{-1}\right)$. Subsequent to saturation, the column was leached with the saturating solution using a Marriot bottle as a constant pressure device (Levy and Torrento, 1995). It was experimentally determined that after two pore volumes of solution had passed through the column, physical and chemical equilibrium had been obtained (data not shown). Thusly, progressively lower salt concentrations were applied at two pore volume intervals. The $\mathrm{HC}$ of each soil was calculated using the Darcy equation (Eq. (5)), where $q=$ measured flux $\left(\mathrm{cm} \mathrm{s}^{-1}\right) ; K=\mathrm{HC}$ $\left(\mathrm{cm} \mathrm{s}^{-1}\right) ; \Delta H=$ change in pressure head ( $\mathrm{cm}$ of water); $\Delta Z=$ change in distance $(\mathrm{cm})$. Saturated HC describes how water is transmitted downward while a soil is saturated and reflects conditions in the soil, such as total porosity, pore size, and tortuosity of pores, as well as characteristics of the soil water, including viscosity and density (Quirk and Schofield, 1955).

$q=-K\left(\frac{\Delta H}{\Delta Z}\right)$

Within each replicate column ( $n=3$ columns per treatment), HC values were calculated for each applied electrolyte concentration (EC) $\left(50,25,12,6,0 \mathrm{mEq} \mathrm{L}^{-1}\right)$. The $\mathrm{HC}$ values were then plotted against the measured $\mathrm{EC}$ of the solution. The $\mathrm{HC}$ values were scaled by the initial $\mathrm{HC}$ of the column (at $50 \mathrm{mEq} \mathrm{L}^{-1}$ ) to obtain a relative $\mathrm{HC}$ value. This approach allowed for comparison of changes in saturated $\mathrm{HC}$ of three soil types at seven different leaching solution treatments, including SAR 3, 6, and 9 and PAR 1, 2, 4, and 9. The $\mathrm{Na}^{+}$ and $\mathrm{K}^{+}$treatments chosen for this study were not identical values, due to the higher affinity of clays for $\mathrm{K}^{+}$, which increases the effective concentration of $\mathrm{K}^{+}$in solution. Greater effective concentration results in a larger increase in EPP at a given PAR than the rise is ESP for the same SAR (Levy and Torrento, 1995). Therefore, the PAR values selected for this study were lower than the SAR values, except for SAR 9 and PAR 9.

\subsection{Ion ratios and ion chromatography}

The leachate of the soil columns ( $n=3$ columns per treatment) was collected as fractions $\leq 30 \mathrm{~mL}$ and analyzed for $\mathrm{pH}$ and EC using a Thermo Scientific Orion 4 Star meter (DuraProbe ${ }^{\mathrm{TM}} 4$-Electrode 


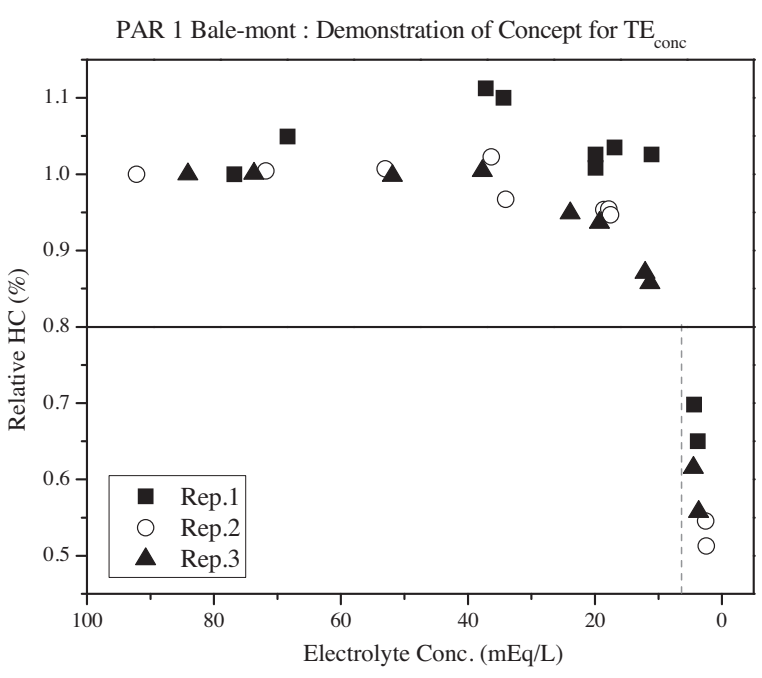

Fig. 1. The $x$-axis represents the soil hydraulic conductivity (HC), scaled by the columns own initial $\mathrm{HC}$, to give a relative $\mathrm{HC}(\%)$. The figure illustrates how the threshold electrolyte concentration $\left(\mathrm{TE}_{\text {conc }}\right)$ can be determined as the average EC where $20 \%$ reduction in relative $\mathrm{HC}$ has occurred, and can be seen as the intersection of the vertical dotted line with the horizontal line at 0.8 relative $\mathrm{HC}$.

Conductivity Cell 013005MD/Accumet Pencil-Thin Epoxy Body Combination-13-620-252) (Burt and Staff, 2014). Cation $\left(\mathrm{Na}^{+}, \mathrm{K}^{+}\right.$, $\left.\mathrm{NH}_{4}^{+}, \mathrm{Mg}^{2+}, \mathrm{Na}^{2+}\right)$ and anion $\left(\mathrm{Cl}^{-}, \mathrm{SO}_{4}{ }^{-}, \mathrm{Br}^{-}, \mathrm{NO}_{3}{ }^{-}, \mathrm{PO}_{4}{ }^{3-}\right)$ concentrations in the column leachate were determined on a Dionex Ion Chromatograph (ICS-2000). Two technical replicates from each leachate sample were run according to standard methods (ASTM, 2009; EPA, 2007). Ion data was used to calculate cation retention, indicating sorption, for each soil column, where delta values were determined by subtracting initial influent from final leachate ion concentrations. Ion data was also used to calculate the total salt concentration $\left(\mathrm{mEq} \mathrm{L}^{-1}\right)$ of the leachate.

\subsection{Experimental design and statistical analysis of changes in hydraulic conductivity}

The column experiments were run as a completely randomized design (CRD) ( $n=3$ columns per treatment). Reductions in HC were discussed as changes in $\mathrm{TE}_{\text {conc }}$ and examined by analysis of variance (ANOVA) (JMP 10, SAS Institute License 2013, Cary, NC, USA). The $\mathrm{TE}_{\text {conc }}$ is equal to the $\mathrm{EC}$ where $20 \%$ reduction in relative $\mathrm{HC}$ has occurred (Fig. 1). For treatments where $\mathrm{HC}$ increased and a $\mathrm{TE}_{\mathrm{conc}}$ was never reached, zero values were assigned for the purpose of statistical analysis (Table 2). A two-way ANOVA was performed on the $\mathrm{TE}_{\text {conc }}$ values, examining main effects of treatment level, soil type, and their interactions, using $P \leq 0.05$ as significant values. The ANOVA showed all factors and interactions to be significant. For this reason the $\mathrm{TE}_{\text {conc }}$ values were then analyzed in two separate one-way ANOVAs. A post-hoc analysis of multiple mean comparisons was performed using a Tukey Honestly Significant Difference test $(P \leq 0.05)$ to examine differences in $\mathrm{TE}_{\text {conc }}$ between treatments with soil type as the fixed effect (Table 2), as well as differences in $\mathrm{TE}_{\text {conc }}$ between soil types, where treatment is the fixed effect (Table 3).

\section{Results}

\subsection{Mineralogy}

Due to the fact that actual vineyard soils were used for this study, the soils are of mixed mineralogies and do not represent pure mineral phases. All soils contained some proportion of
Table 2

Average $\mathrm{TE}_{\mathrm{conc}}(\mathrm{n}=3)$ for all treatments by soil type, increases indicating reduced $\mathrm{HC}$. Lowercase letters indicate significant differences within each soil type. $0=$ No reduction in $\mathrm{HC}$, even with deionized $\mathrm{H}_{2} \mathrm{O}=$ No $\mathrm{TE}_{\text {conc }}$.

\begin{tabular}{|c|c|c|c|}
\hline Soil type & Treatment & Average $\mathrm{TE}_{\text {conc }}$ & SD \\
\hline & & $\mathrm{mEq} \mathrm{L}^{-1}$ & $\mathrm{mEqL}^{-1}$ \\
\hline \multirow[t]{7}{*}{ Bale-mont } & SAR 3 & $16.0_{a}$ & 4.3 \\
\hline & SAR 6 & $13.4 \mathrm{a}$ & 2.2 \\
\hline & SAR 9 & $15.7 \mathrm{a}$ & 4.4 \\
\hline & PAR 1 & $6.0_{\mathrm{a}}$ & 1.9 \\
\hline & PAR 2 & $7.5 \mathrm{a}$ & 3.4 \\
\hline & PAR 4 & $13.9 \mathrm{a}$ & 0.4 \\
\hline & PAR 9 & $13.5 \mathrm{a}$ & 6.1 \\
\hline \multirow[t]{7}{*}{ Red-kao } & SAR 3 & $0.0_{\mathrm{a}}$ & 0.0 \\
\hline & SAR 6 & $0.0_{\mathrm{a}}$ & 0.0 \\
\hline & SAR 9 & $0.0_{a}$ & 0.0 \\
\hline & PAR 1 & $0.0_{a}$ & 0.0 \\
\hline & PAR 2 & $0.0_{a}$ & 0.0 \\
\hline & PAR 4 & $8.8_{\mathrm{b}}$ & 6.1 \\
\hline & PAR 9 & $7.4_{b}$ & 0.1 \\
\hline \multirow[t]{7}{*}{ SJ-ver } & SAR 3 & $7.2 \mathrm{a}$ & 0.5 \\
\hline & SAR 6 & $9.9 \mathrm{a}$ & 2.0 \\
\hline & SAR 9 & $28.8_{b}$ & 15.1 \\
\hline & PAR 1 & $7.5_{a}$ & 4.6 \\
\hline & PAR 2 & $9.4 \mathrm{a}$ & 0.2 \\
\hline & PAR 4 & $12.1_{\mathrm{ab}}$ & 5.2 \\
\hline & PAR 9 & $21.3_{\mathrm{ab}}$ & 5.0 \\
\hline
\end{tabular}

$\mathrm{TE}_{\mathrm{conc}}=$ threshold electrolyte concentration; $\mathrm{SAR}=$ sodium absorption ratio; PAR = potassium absorption ratio; $\mathrm{SD}=$ standard deviation; Bale-mont = montmorillonite rich soil; Red-kao = kaolinite rich soil; SJ ver = vermiculite rich soil. $\mathrm{SD}=$ standard deviation.

Table 3

Average $\mathrm{TE}_{\text {conc }}(n=3)$ for each soil type by treatment, increases indicating reduced HC. Lowercase letters indicate significant differences at each soil type (across rows) $0=$ No reduction in $\mathrm{HC}$, even with deionized $\mathrm{H}_{2} \mathrm{O}=$ No $\mathrm{TE}_{\text {conc }}$.

\begin{tabular}{cclc}
\hline & Bale-mont & Red-kao & SJ-ver \\
\hline SAR 3 & $16.0_{\mathrm{a}}$ & $0.0_{\mathrm{b}}$ & $7.2_{\mathrm{c}}$ \\
SAR 6 & $13.4_{\mathrm{a}}$ & $0.0_{\mathrm{b}}$ & $9.9_{\mathrm{a}}$ \\
SAR 9 & $15.7_{\mathrm{ab}}$ & $0.0_{\mathrm{b}}$ & $28.8_{\mathrm{a}}$ \\
PAR 1 & $6.0_{\mathrm{ab}}$ & $0.0_{\mathrm{b}}$ & $7.5_{\mathrm{a}}$ \\
PAR 2 & $7.5_{\mathrm{a}}$ & $0.0_{\mathrm{b}}$ & $9.4_{\mathrm{a}}$ \\
PAR 4 & $13.9_{\mathrm{a}}$ & $8.8_{\mathrm{a}}$ & $12.1_{\mathrm{a}}$ \\
PAR 9 & $13.5_{\mathrm{ab}}$ & $7.4_{\mathrm{b}}$ & $21.3_{\mathrm{a}}$ \\
\hline
\end{tabular}

$\mathrm{TE}_{\text {conc }}=$ threshold electrolyte concentration: $\mathrm{SAR}=$ sodium absorption ratio; $\mathrm{PAR}=$ potassium absorption ratio; Bale-mont $=$ montmorillonite rich soil; Red-kao = kaolinite rich soil; SJ-ver = vermiculite rich soil.

kaolinite and mica, but montmorillonite was only found in the Bale-mont and vermiculite was unique to the SJ-ver. The Bale-mont contained montmorillonite, mica, and kaolinite (Table 1). It had the highest activity of the three soils and exhibited no measurable $\mathrm{K}^{+}$fixation. The Red-kao was confirmed to contain kaolinite and mica, and it also had no $\mathrm{K}^{+}$-fixation potential (Table 1 ). The SJ-ver soil contained vermiculite as well as kaolinite and mica. It was in the super-active class and had high $\mathrm{K}^{+}$-fixation potential (Table 1 ).

\subsection{Changes in soil hydraulic conductivity}

Increases in the $\mathrm{TE}_{\text {conc }}$ can be equated to a decrease in HC. The Bale-mont maintained a $\mathrm{TE}_{\text {conc }}$ close to $15 \mathrm{mEq} \mathrm{L}^{-1}$ for all SAR treatments (Fig. 2a). For the Bale-mont, no differences in decreasing HC was observed between any of the SAR treatments (Fig. 2a), nor for the PAR treatments (Fig. 3a). However, the PAR columns maintained a lower average $\mathrm{TE}_{\text {conc }}\left(6-13.9 \mathrm{mEq} \mathrm{L}^{-1}\right.$-Table 2) than the SAR columns, but differences were only marginally significant $(P=0.056)$. The SAR treatments did not reduce the HC of the Redkao (Fig. 2b), while the higher PAR treatments did (Fig. 3b). The HC 


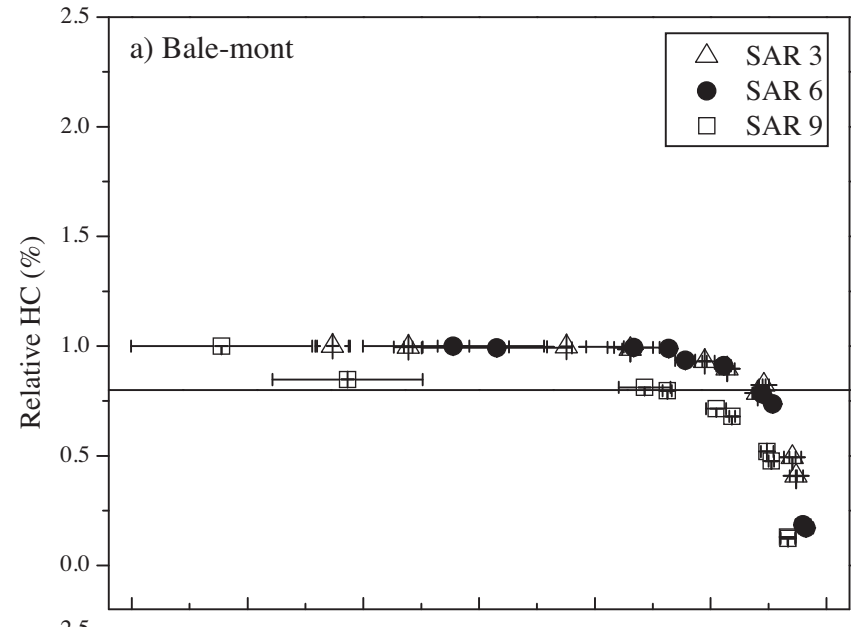

b) Red-kao
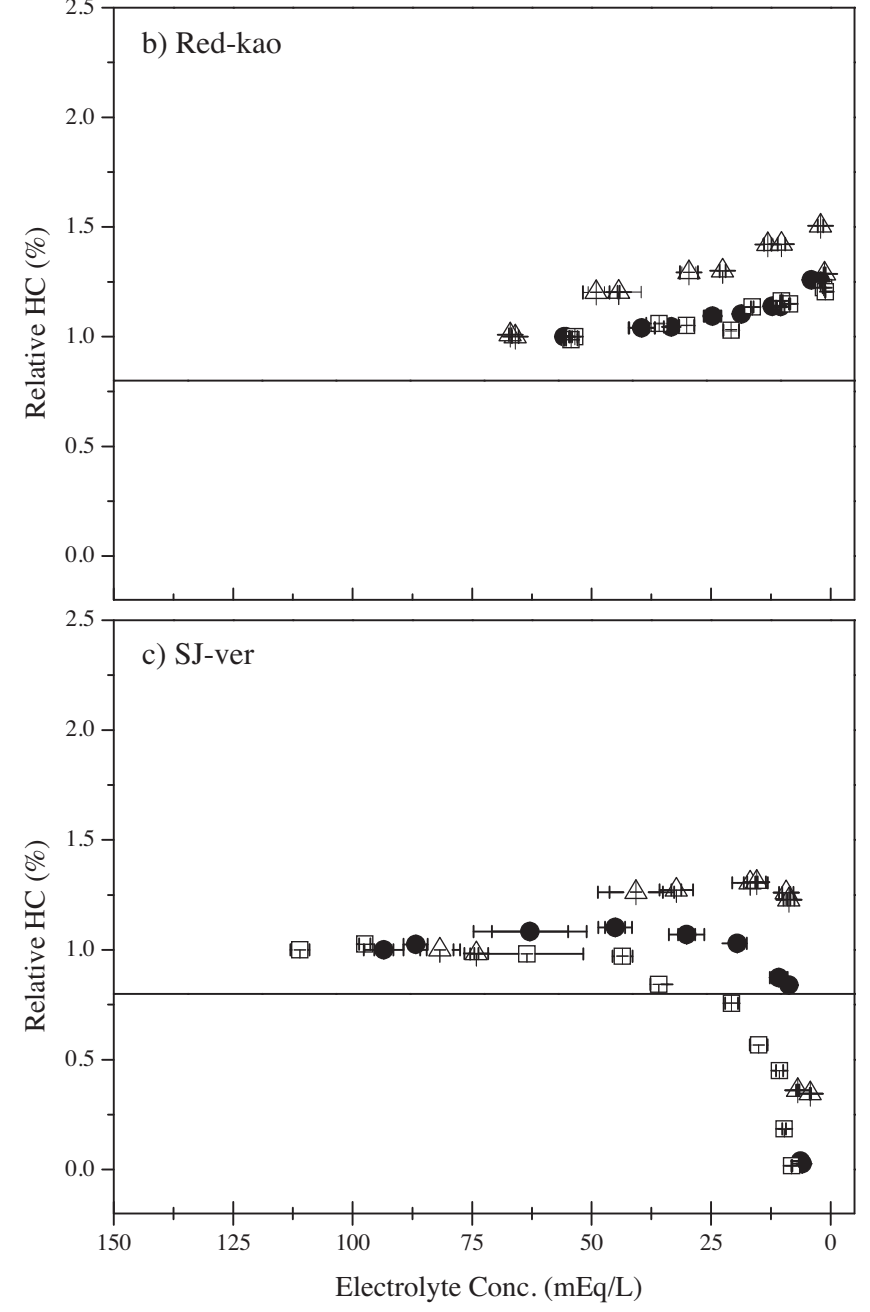

Fig. 2. The $x$-axis represents the soil hydraulic conductivity (HC), scaled by the columns own initial HC, to give a relative $\mathrm{HC}$ (\%). Changes in relative $\mathrm{HC}$ of (a) Balemont, (b) Red-kao, and (c) SJ-ver soil with decreasing EC for all SAR treatments. Average of three column replicates with error bars representing one standard error of the mean. Where open symbols are used, error bars smaller than the symbol size appear as marks inside the open symbol. The line indicates $20 \%$ reduction in relative $\mathrm{HC}$ and is used to determine the threshold electrolyte concentration ( $\mathrm{TE}_{\text {conc }}$.). Relative $\mathrm{HC}=$ hydraulic conductivity scaled to initial hydraulic conductivity of the column; Bale-mont = montmorillonite rich soil; Red-kao = kaolinite rich soil; SJ-ver $=$ vermiculite rich soil.
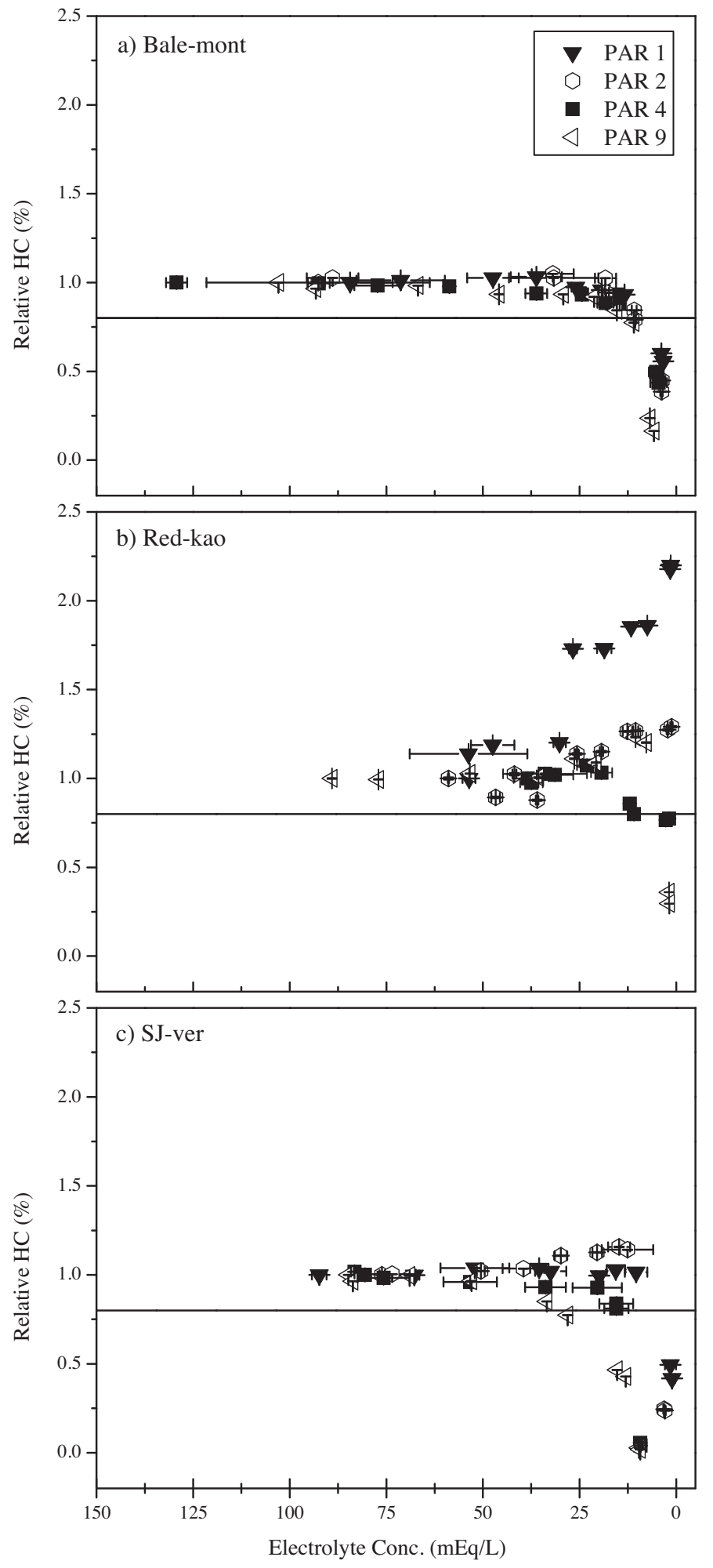

Fig. 3. The $x$-axis represents the soil hydraulic conductivity (HC), scaled by its own initial HC, to give a relative HC (\%). Changes in relative HC of (a) Bale-mont, (b) Redkao, and (c) SJ-ver soil with decreasing EC for all PAR treatments. Average of three column replicates with error bars representing one standard error of the mean. Where open symbols are used, error bars smaller than the symbol size appear as marks inside the open symbol. The line indicates $20 \%$ reduction in relative $\mathrm{HC}$ and is used to determine the $\mathrm{TE}_{\text {conc }}$. Relative $\mathrm{HC}=$ hydraulic conductivity scaled to initial hydraulic conductivity of the column; Bale-mont = montmorillonite rich soil; Redkao = kaolinite rich soil; SJ-ver = vermiculite rich soil; EC = electrolyte concentration; $\mathrm{TE}_{\mathrm{conc}}=$ threshold electrolyte concentration. 
of the Red-kao was not reduced, and thusly a $\mathrm{TE}_{\text {conc }}$ was not reached for any SAR treatments, nor at PAR 1 and 2 (Table 2). At PAR 4 and 9 the $\mathrm{TE}_{\text {conc }}$ increased to $8.8 \mathrm{mEq} \mathrm{L}^{-1}$ and $7.4 \mathrm{mEq} \mathrm{L}^{-1}$, respectively (Fig. 3b). In the SJ-ver soil, a decrease in HC was observed with both increasing SAR and PAR. The decrease in HC was only significant at SAR 9, where the $\mathrm{TE}_{\text {conc }}$ increased to $28.8 \mathrm{mEq} \mathrm{L}^{-1}$ (Table 2).

In summary, the $\mathrm{HC}$ of the Bale-mont was not significantly reduced within the range of tested SAR and PAR values. The HC of the Red-kao and the SJ-ver soils was reduced with increasing ratios of monovalent to divalent ions (e.g., increasing SAR and PAR), except for the Red-kao with SAR treatments. Reductions in HC were strongly influenced by soil mineralogy, as demonstrated by the differences in $\mathrm{TE}_{\text {conc }}$ between soil types at the same SAR or PAR treatment (Table 3).

\subsection{Changes in ion concentration in column leachate}

Changes in ion concentrations relative to the initial leaching solutions were calculated from the final leachate fractions of each column ( $n=3$ columns per treatment). These data were used to infer sorption and leaching of ions on the exchange complex. The changes in cation concentrations seen in the SAR 9 and PAR 9 leachate are depicted in Figs. 4 and 5, with positive values indicating leaching and negative values indicating sorption. All other treatments showed similar trends in data, and those treatments are included in Appendix A.

The Bale-mont and the SJ-ver showed similar retention of $\mathrm{Na}^{+}$ and $\mathrm{K}^{+}$and leaching of $\mathrm{Ca}^{2+}$. Both soils sorbed $\mathrm{Na}^{+}$only at SAR 9 , indicating that the $\mathrm{Na}^{+}$displaced $\mathrm{Ca}^{2+}$ at that treatment. Both the Bale-mont and the SJ-ver exhibited increased $\mathrm{K}^{+}$sorption with increasing PAR (Appendix A). For both soils, $\mathrm{Ca}^{2+}$ leaching increased with increasing SAR and PAR (Appendix A). However, while the Bale-mont leached 5-20 mEq L ${ }^{-1}$ of $\mathrm{Mg}^{2+}$ only at SAR 9 and PAR 9 (Figs. $4 \mathrm{a}$ and $5 \mathrm{a}$ ), the SJ-ver experienced leaching of $5-25 \mathrm{mEq} \mathrm{L}^{-1}$ of $\mathrm{Mg}^{2+}$ at all treatments (Appendix A).

The Red-kao differed from the other two soils in its interaction with cations in solution. Unlike the other two soils, no changes in $\mathrm{Mg}^{2+}$ concentrations were seen in any treatment (Appendix A). Opposite to the Bale-mont and SJ-ver, $\mathrm{Ca}^{2+}$ leaching in the Red-kao soil decreased with increasing SAR (Appendix A).

All three soils showed increased $\mathrm{K}^{+}$sorption with increasing PAR (Appendix A), and the maximum amount of $\mathrm{K}^{+}$retained in the columns (up to $\sim 30 \mathrm{mEq} \mathrm{L}^{-1}$ ) was nearly three times that of the maximum amount of $\mathrm{Na}^{+}$retained (Figs. 4 and 5). In general, the sorption of $\mathrm{K}^{+}$was preferred over $\mathrm{Na}^{+}$.

Anion concentrations of the leachate fractions closely matched anion concentrations in the introduced solution, indicating that little interaction with the negatively charged soil surfaces occurred and thus are not discussed here.

\section{Discussion}

Through the controlled variation of solution salinity, SAR, and PAR, the effects of certain mineral-cation relationships on HC can be elucidated. The $\mathrm{TE}_{\mathrm{conc}}$ values obtained for the three different soils show that the mineralogy of the soil, EC (measure of salinity), and the ratio of monovalent to divalent cations in solution (e.g., SAR, PAR) influence reductions in soil HC.

\subsection{Effects of sodium on soil hydraulic conductivity}

As described in previous studies, the negative effects of $\mathrm{Na}^{+}$are most pronounced in soils which are high in clay, especially high charge density clays (Frenkel et al., 1978). In the current study, the soils in higher activity classes (Bale-mont and SJ-ver) were more susceptible to reductions in $\mathrm{HC}$ by higher $\mathrm{Na}^{+}$solutions, than the
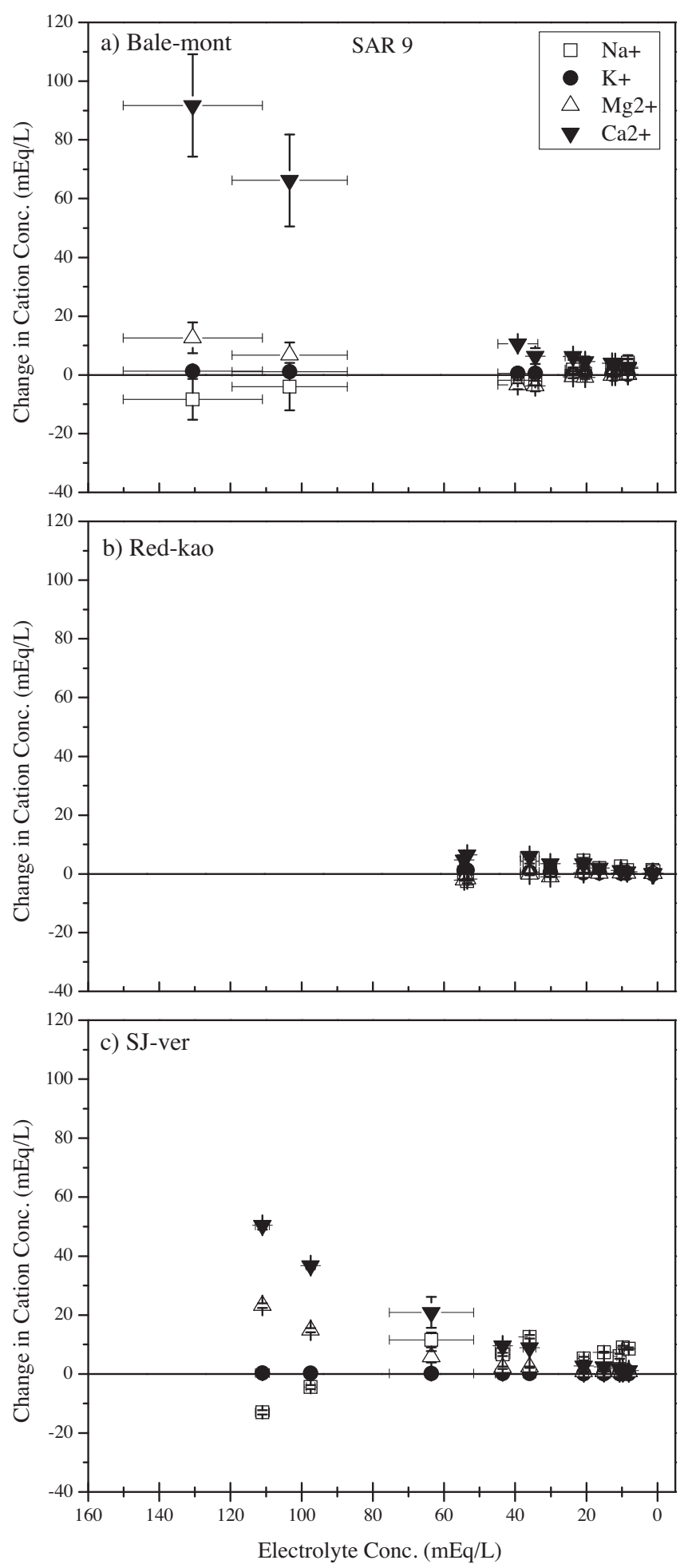

Fig. 4. Change in cation concentration of (a) Bale-mont, (b) Red-kao, and (c) SJ-ver soil at SAR 9. Average of three column replicates with error bars representing one standard error of the mean. Where open symbols are used, error bars smaller than the symbol size appear as marks inside the open symbol. Points above the zero line show leaching and points below it show sorption. Bale-mont $=$ montmorillonite rich soil; Red-kao = kaolinite rich soil; SJ-ver = vermiculite rich soil; SAR = sodium adsorption ratio.

less reactive Red-kao soil. The tendency of $\mathrm{Na}^{+}$ions to facilitate the formation of multiple ( 3 or 4 ) layer hydrates in smectite clays leads to greater swelling and reduction of HC (Anderson et al., 2010). The $\mathrm{TE}_{\text {conc }}$ did not increase for the Bale-mont in any of the SAR treatments, but it can be concluded that the $\mathrm{HC}$ of the Bale-mont 

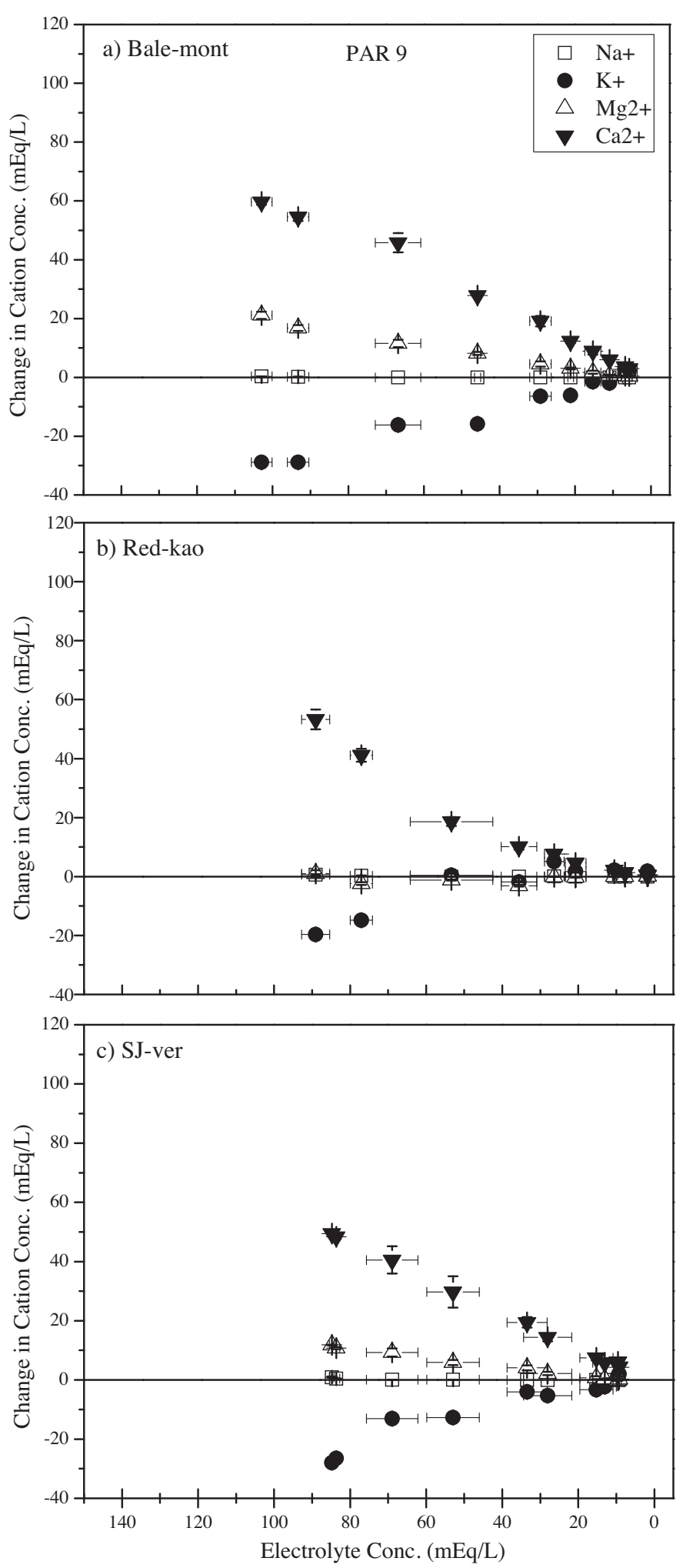

Fig. 5. Change in cation concentration of (a) Bale-mont, (b) Red-kao, and (c) SJ-ver soil at PAR 9. Average of three column replicates with error bars representing one standard error of the mean. Where open symbols are used, error bars smaller than the symbol size appear as marks inside the open symbol. Points above the zero line show leaching and points below it show sorption. Bale-mont $=$ montmorillonite rich soil; Red-kao = kaolinite rich soil; SJ-ver = vermiculite rich soil; PAR = potassium adsorption ratio. soil was reduced by all SAR treatments. This conclusion is based on the higher $\mathrm{TE}_{\text {conc }}$ for all SAR treatments (although not significant), compared to the PAR 1 treatment. The Bale-mont soil in the current study was $19.7 \%$ clay and showed continued release of $\mathrm{Ca}^{2+}$. Removal of divalent ions from the exchange complex can contribute to reductions in aggregate stability and decreases in HC of the SAR treatments (Kopittke et al., 2006). The large increase in $\mathrm{Ca}^{2+}$ concentration in the leachate of the Bale-mont columns was accompanied by a removal of $\mathrm{Na}^{+}$from solution and strongly suggests that $\mathrm{Na}^{+}$for $\mathrm{Ca}^{2+}$ exchange was occurring at SAR 9 (Fig. 4a). The preferential affinity of montmorillonite clay for $\mathrm{Na}^{+}$over $\mathrm{Ca}^{2+}$ is well documented and has been shown to increase with increasing salt concentration of the soil solution and to decrease with increasing SAR (Endo et al., 2002). A review of $\mathrm{Na}^{+}$-rich wastewater reuse for irrigation found that swelling dominated at high ESP, while dispersion dominated at low ESP (Halliwell et al., 2001). In the larger context of Halliwell's review, the SAR 3, 6, and 9 treatments included in our study would be described as low ESP. The abrupt reductions in HC in the Bale-mont and SJ-ver SAR treatments indicate that dispersion is likely the dominant mechanism reducing $\mathrm{HC}$.

The $\mathrm{TE}_{\text {conc }}$ of the SJ-ver soil was lower than that of the Balemont at SAR 3, suggesting that the SJ-ver soil was more stable than the Bale-mont at lower $\mathrm{Na}^{+}$concentrations (Table 3 ). However, at SAR 9 the $\mathrm{TE}_{\text {conc }}$ of the SJ-ver increased to $28.8 \mathrm{mEq} \mathrm{L}^{-1}$ and did not differ from the Bale-mont at that treatment, confirming that the $\mathrm{HC}$ of both the SJ-ver and the Bale-mont was affected at the SAR 9 treatment (Table 2). Also, similar to the Bale-mont, in the SAR 9 treatment of SJ-ver soil, divalent cations were lost as $\mathrm{Na}^{+}$was sorbed, implicating the dispersive effects of increasing $\mathrm{Na}^{+}$as the cause of reduced HC in the SJ-ver soil as well (Fig. 4c).

The lack of reductions in $\mathrm{HC}$ of the Red-kao as a result of increasing $\mathrm{Na}^{+}$concentrations can be explained by various mechanisms (Fig. 2b). Increases in HC have been attributed to physical rearrangement of particles in situ and washing out of finer particles (Arienzo et al., 2012; Frenkel et al., 1978). It is possible that high anion concentrations interacted with positively charged edge sites in the Red-kao, leading to dispersion, washing out of clay, and increased HC (Frenkel et al., 1992). Increasing HC may also be caused by using flow rates that are faster than field conditions, leading to physical disruption (D. Suarez, pers. comm. 2011). Kaolinite soils have been seen to have positive charge at low $\mathrm{pH}$, due to proton acceptance on edge sites (Moshi et al., 1974). Since the Red-kao soil used in this study had a CEC of $10 \mathrm{mEq} \mathrm{L}^{-1}$ and a $\mathrm{pH}$ of 5 , it is reasonable to assume that the kaolinite clay in this soil may have presented some positive charge and therefore did not bind the introduced cations. For example, unlike the other two soils, the relatively low activity of the Red-kao resulted in a minimal interaction with $\mathrm{Na}^{+}$and no leaching of $\mathrm{Ca}^{2+}$ or $\mathrm{Mg}^{2+}$ in the SAR 9 treatment solution (see Fig. 4b). These cation data, considered alongside the lack of reduction in $\mathrm{HC}$ (Fig. 2b), indicate that SAR solutions had no negative effect on the HC of the Red-kao soil.

\subsection{Effects of potassium on soil hydraulic conductivity}

Similar to the SAR treatments of the Bale-mont and SJ-ver, abrupt reductions in HC were seen for the PAR treatments, suggesting that dispersion is also the dominant mechanism affecting $\mathrm{HC}$ at the represented concentrations of $\mathrm{K}^{+}$. However, a stabilizing effect of $\mathrm{K}^{+}$with smectite is demonstrated by the Bale-mont soil, where the average $T E_{\text {conc }}$ for PAR treatments was lower (not significant) than for the SAR treatments and no increases in the $\mathrm{TE}_{\text {conc }}$ occurred at any PAR treatment. The stabilizing effects of $\mathrm{K}^{+}$, washing out of clays, or flow rates above field capacity also offer explanations for the slight increases in $\mathrm{HC}$ seen above the $\mathrm{TE}_{\text {conc. in both the Bale- }}$ mont and SJ-ver soil (Fig. 5). When adsorbed on the outer surfaces of 
clay aggregates, $\mathrm{K}^{+}$has the potential to reduce dispersion by compressing the diffuse ion layer (i.e., the Gouy-Chapman model of the electric double layer), but it could also increase dispersion if present at high concentrations on the exchange complex (Sposito, 1989). The hydration energy of $\mathrm{K}^{+}$is only $72 \%$ that of $\mathrm{Na}^{+}$and consequently, in high charge density smectites, where there are strong attractive forces present between clay particles, the low hydration energy of exchangeable $\mathrm{K}^{+}$helps to limit dispersion (Anderson et al., 2010; Levy and Torrento, 1995). The amount of $\mathrm{K}^{+}$retained in the PAR columns was on average three times greater than the $\mathrm{Na}^{+}$retained in the SAR columns, indicating the overall higher affinity of the Bale-mont soil for $\mathrm{K}^{+}$. However, $\mathrm{HC}$ did not decrease for any PAR treatments of the Bale-mont soil, despite the leaching of $\mathrm{Ca}^{2+}$ and preferential retention of $\mathrm{K}^{+}$.

Like the Bale-mont, the SJ-ver soil also showed signs of preferential sorption of $\mathrm{K}^{+}$with increasing PAR, as indicated by the increased retention of $\mathrm{K}^{+}$and increased $\mathrm{Ca}^{2+}$ leaching (Appendix A). However, for all treatments in the SJ-ver soil leaching of $\mathrm{Mg}^{2+}$ was observed and may have contributed to the equally destabilizing effects of both $\mathrm{Na}^{+}$and $\mathrm{K}^{+}$in this soil type (Figs. $4 \mathrm{c}$ and $5 \mathrm{c}$ ).

The reductions in $\mathrm{HC}$ of the Red-kao soil differed from the other soils in this study. The HC of the Bale-mont and SJ-ver soils experienced similar trends in reduction for SAR and PAR treatments, while in the Red-kao soil the PAR 4 and 9 treatments clearly differed from all other treatments. In the Red-kao, the HC increased with increasing SAR (Fig. 1b), possibly due to the flocculating effects of increasing soil salinity (Levy and Torrento, 1995). The Red-kao soil was dominated by minerals with 1:1 layer structure, which do not have an interlayer space and therefore do not exhibit osmotic swelling. However, HC of the Red-kao decreased in the high PAR treatments (Fig. 2b). At PAR 4 and 9, the increases in $\mathrm{TE}_{\text {conc }}$ to 8.8 $\mathrm{mEq} \mathrm{L} \mathrm{L}^{-1}$ and $7.4 \mathrm{mEq} \mathrm{L}^{-1}$, respectively, were an indication of the possible negative effects of $\mathrm{K}^{+}$on soil $\mathrm{HC}$ (Table 2 ). In the Red-kao PAR 9 columns, where evidence of a $\mathrm{Ca}^{2+}$ for $\mathrm{K}^{+}$exchange was observed, the HC of the soil was reduced. In the Red-kao PAR 9 columns, retention of $\mathrm{K}^{+}$was seen when $\mathrm{EC} \geq 65 \mathrm{mEq} \mathrm{L}^{-1}$ (Fig. 5b), while there was no indication of $\mathrm{Na}^{+}$sorption for any of the SAR treatments (Fig. 4b). This discrepancy in cation sorption could be attributed to the presence of mica in the Red-kao, possibly due to mica's high preference for $\mathrm{K}^{+}$(Sposito, 1989). Increases in soil EPP above 20 reduced $\mathrm{HC}$ in three soils, each containing montmorillonite, kaolinite, and illite, (Chen et al., 1983). The affinity of the Red-kao for $\mathrm{K}^{+}$may have led to a greater increase in EPP in the PAR treatments than the rise in ESP for the comparable SAR treatments, causing dispersive behavior in the Red-kao at PAR 4 and 9 and consequent reductions in HC. In soils high in kaolinite or illite, $\mathrm{K}^{+}$behaves more like what is typical for $\mathrm{Na}^{+}$(Shainberg et al., 1980). These varied responses may also be influenced by the ability of certain clay minerals (e.g. vermiculite) to selectively adsorb $\mathrm{K}^{+}$ (O'Geen et al., 2008; Oster, 1994). Only a few investigations specific to kaolinite and $\mathrm{K}^{+}$interactions have been conducted and further studies examining the impact of $\mathrm{K}^{+}$on the $\mathrm{HC}$ of kaolinitic soils is required (Chen et al., 1983; Laurenson et al., 2011).

\subsection{Effects of cation ratios on soil hydraulic conductivity}

The effects of $\mathrm{Na}^{+}$and $\mathrm{K}^{+}$on soil $\mathrm{HC}$ depend on the concentration of divalent cations $\left(\mathrm{Ca}^{2+}\right.$ and $\mathrm{Mg}^{2+}$ ) in solution. The SJ-ver soil was more sensitive to the overall increasing ratio of the monovalent to divalent ions (e.g., increases in SAR and PAR), rather than which particular ion $\left(\mathrm{Na}^{+}\right.$or $\mathrm{K}^{+}$) was present. For example, at both the low SAR and low PAR treatments, slight increasing trends in $\mathrm{HC}$ showed the stabilizing effects of $\mathrm{Na}^{+}$and $\mathrm{K}^{+}$salts when the leaching solution was above the $\mathrm{TE}_{\text {conc }}$ (Figs. $2 \mathrm{c}$ and $3 \mathrm{c}$, respectively). For the SJ-ver soil, more $\mathrm{K}^{+}$was removed from the leachate of the PAR columns than $\mathrm{Na}^{+}$from the SAR columns, indicating that
$\mathrm{K}^{+}$was more competitive for binding sites in this soil, however, reductions in HC occurred at both SAR 9 and PAR 9 (to 28.8 and $21.3 \mathrm{mEq} \mathrm{L}^{-1}$, respectively). In contrast, in the Bale-mont soil HC was not significantly reduced at SAR 9 or PAR 9 . This suggests that soils dominated by vermiculite may be more sensitive to increases in $\mathrm{K}^{+}$concentrations than those with high amounts of montmorillonite. The lower layer charge associated with $\mathrm{K}^{+}$-fixation of the SJ-ver may have allowed $\mathrm{K}^{+}$to hydrate fully, which would have increased swelling and dispersion (Bower and Rhoades, 1972). In the Bale-mont, higher charge and tighter interlayer spacing could have minimized the hydrated layer and consequent swelling associated with $\mathrm{K}^{+}$ions (Anderson et al., 2010). In the Bale-mont soil, both the observed loss of $\mathrm{Ca}^{2+}$ in the SAR and PAR columns (Figs. $4 \mathrm{a}$ and $5 \mathrm{a}$ ), and the similar $\mathrm{TE}_{\mathrm{conc}}$ for all treatments, indicated that the $\mathrm{HC}$ of the Bale-mont was equally effected by the presence of $\mathrm{Na}^{+}$ and $\mathrm{K}^{+}$within the tested concentration ranges.

\section{Conclusion}

Parts of the United States, including Northern California, are currently experiencing drought conditions that could have profound reverberations on the economy and devastating environmental impacts. The reuse of WW for irrigation is one practical approach to mitigating the impacts of the current drought in agricultural industries, including wine production. From the results of the current study, it can be concluded that WW is a viable alternative water source for irrigation of landscaping and crops. The dominant soil mineralogy and the presence of $\mathrm{Na}^{+}$and $\mathrm{K}^{+}$in influent solution were critical factors influencing $\mathrm{HC}$ of the tested soils. The soils with higher charge density and expandable phyllosilicate interlayers (Bale-mont and SJ-ver) were more susceptible to reductions in $\mathrm{HC}$ when treated with $\mathrm{Na}^{+}$solutions. When considering the reuse of WW on soils dominant in montmorillonite clay, the use of $\mathrm{K}^{+}$-based, as opposed to $\mathrm{Na}^{+}$-based cleaners is recommended. PAR solutions $\leq 2$ had no negative effects on HC in any of the soils included in this study. Solutions with PAR $\geq 4$ did negatively impact water movement in soils with a high affinity for $\mathrm{K}^{+}$. The SJ-ver soil contained vermiculite and mica (minerals with high $\mathrm{K}^{+}$-fixation potential), and mica was also present in the Red-kao soil, suggesting that the interlayer binding of $\mathrm{K}^{+}$leads to greater reductions in $\mathrm{HC}$. However, WW with SAR and PAR values $\leq 9$ do not present a major threat to soil HC if the total salinity of the solution $\geq 25 \mathrm{mEq} \mathrm{L}^{-1}$, and any accumulation of $\mathrm{Na}^{+}$or $\mathrm{K}^{+}$in the soil profile are easily managed with additions of $\mathrm{Ca}^{2+}$ in the form of gypsum (Weber et al., 2014). Further research on the impact of mineral-ion interactions on $\mathrm{HC}$ in additional soils and pure mineral systems is necessary in order to better understand high risk scenarios that may arise when irrigating with $\mathrm{K}^{+}$-rich WW. Reuse of WW must be carefully considered and full analysis of soil and WW is recommended prior to land applications for landscaping or crop irrigation.

\section{Acknowledgements}

Thank you to Randy Dahlgren and Xien Wang for assistance with ion analysis and to Timothy A. Doan for support with nitrate analysis. Thank you to the Kearney Foundation of Soil Science, Grant \#2009.011, and to the Henry A. Jastro-Shields Scholarship funds awarded through the University of California Davis, Soils and Biogeochemistry Graduate Group.

\section{Appendix A. Supplementary data}

Supplementary data associated with this article can be found, in the online version, at http://dx.doi.org/10.1016/j.agwat. 2015.01.015. 


\section{References}

Abusharar, T.M., Bingham, F.T., Rhoades, J.D., 1987. Reduction in hydraulic conductivity in relation to clay dispersion and disaggregation. Soil Sci. Soc. Am. J. 51, 342-346.

Anderson, R.L., Ratcliffe, I., Greenwell, H.C., Williams, P.A., Cliffe, S., Coveney, P.V., 2010. Clay swelling-a challenge in the oilfield. Earth-Sci. Rev. 98, 201-216.

Arienzo, M., Christen, E.W., Jayawardane, N.S., Quayle, W.C., 2012. The relative effects of sodium and potassium on soil hydraulic conductivity and implications for winery wastewater management. Geoderma 173, 303-310.

ASTM, 2009. D6919-09 Standard Test Method for Determination of Dissolved Alkali and Alkaline Earth Cations and Ammonium in Water and Wastewater by Ion Chromatography ASTM International American Society for Testing and Materials. ASTM.

Ayers, R.S., Westcot, D.W., 1985. Water Quality for Agriculture, second ed. Food and Agriculture Organization of the United Nations, Rome.

Benitez, F.J., Beltran-Heredia, J., Real, F.J., Acero, J.L., 1999. Purification kinetics of winery wastes by ozonation, anaerobic digestion and ozonation plus anaerobic digestion. J. Environ. Sci. Health A 34, 2023-2041.

Bower, C.A., Rhoades, J.D., 1972. Fractionation of cation-exchange capacity for assessing soil and water sodicity. Soil Sci. Soc. Am. Pro. 36, 174-\&.

Buelow, M.B., 2013. Properties of Winery Wastewater and the Effects of Treated Wastewater Applications on Soil Hydraulic Conductivity, Land, Air, Water Resources. University of California, Davis, Davis, CA, pp. 141.

Burt, R., Staff, S.S., 2014. Kellog soil survey laboratory methods manual. In: U.S.D.o.A. (Ed.), Natural Resources Conservation Services. National Soil Survey Center, Lincoln, Nebraska.

Bustamante, M.A., Paredes, C., Moral, R., Moreno-Caselles, J., Perez-Espinosa, A., Perez-Murcia, M.D., 2005. Uses of winery and distillery effluents in agriculture: characterisation of nutrient and hazardous components. Water Sci. Technol. 51, 145-151.

Chen, Y., Banin, A., Borochovitch, A., 1983. Effect of potassium on soil structure in relation to hydraulic conductivity. Geoderma 30, 135-147.

Christen, E.W., Quayle, W.C., Marcoux, M.A., Arienzo, M., Jayawardane, N.S., 2010. Winery wastewater treatment using the land filter technique. J. Environ. Manage $91,1665-1673$

Churchman, G.J., Skjemstad, J.O., Oades, J.M., 1993. Influence of clay-minerals and organic-matter on effects of sodicity on soils. Aust. J. Soil Res. 31, 779-800.

Endo, T., Yamamoto, S., Honna, T., Eneji, A.E., 2002. Sodium-calcium exchange selectivity as influenced by clay minerals and composition. Soil Sci. 167, 117-125

EPA, U.S., 2007. In: EPA, U.S. (Ed.), 4110 Determination of Anions by Ion Chromatography. EPA, U.S.

Essington M., Soil and Water Chemistry: An Integrative Approach, 2004, CRC Press Boca Raton, Florida, 0849312582.

Frenkel, H., Goertzen, J.O., Rhoades, J.D., 1978. Effects of Clay Type and Content, Exchangeable Sodium Percentage, and Electrolyte Concentration on Clay Dispersion and Soil Hydraulic Conductivity. Soil Sci. Soc. Am. J. 42, 32-39.

Frenkel, H., Levy, G.J., Fey, M.V., 1992. Clay dispersion and hydraulic conductivity of clay-sand mixtures as affected by the addition of various anions. Clay Clay Miner. 40, 515-521.

Frenkel, H.a.M., A., 1985. Soil Salinity: Two Decades of Reserach in Inrrigated Agriculture.

Halliwell, D.J., Barlow, K.M., Nash, D.M., 2001. A review of the effects of wastewater sodium on soil physical properties and their implications for irrigation systems. Aust. J. Soil Res. 39, 1259-1267.

Hamilton, A.J., Stagnitti, F., Xiong, X.Z., Kreidl, S.L., Benke, K.K., Maher, P., 2007. Wastewater irrigation: the state of play. Vadose Zone J. 6, 823-840.

Hermon, S., Grange, D., Pellet, Y., Lloret, G., Oyonarte, S., Bosch, F., Coste, M., 2008. Zero liquid discharge approach in plating industry: treatment of degreasing effluents by electrocoagulation and anodic oxidation. Water Sci. Technol. 58, 519-527.

Jayawardane, N.S., Christen, E.W., Arienzo, M., Quayle, W.C., 2011. Evaluation of the effects of cation combinations on soil hydraulic conductivity. Soil Res. 49, 56-64.

Keren, R., Singer, M.J., 1988. Effect of low electrolyte concentration on hydraulic conductivity of sodium calcium-montmorillonite-sand system. Soil Sci. Soc. Am. J. 52, 368-373.

Keren, R., Singer, M.J., 1989. Effect of low electrolyte concentration on hydraulic conductivity of clay sand hydroxy polymers systems. Soil Sci. Soc. Am. J. 53, 349-355.
Kopittke, P.M., So, H.B., Menzies, N.W., 2006. Effect of ionic strength and clay mineralogy on Na-Ca exchange and the SAR-ESP relationship. Eur. J. Soil Sci. 57, 626-633.

Laurenson, S., Bolan, N.S., Smith, E., Mccarthy, M., 2012. Review: Use of Recycled Wastewater for Irrigating Grapevines. Australian Society of Viticulture and Oenology Inc., pp. 1-10.

Laurenson, S., Smith, E., Bolan, N.S., McCarthy, M., 2011. Effect of $\mathrm{K}^{+}$on $\mathrm{Na}-\mathrm{Ca}$ exchange and the SAR-ESP Relationship. Soil Res. 49, 538-546.

Levy, G.J., Torrento, J.R., 1995. Clay dispersion and macroaggregate stability as affected by exchangeable potassium and sodium. Soil Sci. 160, 352-358.

McNeal, B.L., Coleman, N.T., 1966. Effect of solution composition on soil hydraulic conductivity. Soil Sci. Soc. Am. Pro. 30, 308.

Mendoza-Espinosa, L.G., Cabello-Pasini, A., Macias-Carranza, V., Daessle-Heuser, W. Orozco-Borbon, M.V., Quintanilla-Montoya, A.L., 2008. The effect of reclaimed wastewater on the quality and growth of grapevines. Water Sci. Technol. 57, 1445-1450.

Moshi, A.O., Wild, A., Greenlan, D.j., 1974. Effect of organic-matter on charge and phosphate adsorption characteristics of Kikuyu Red Clay from Kenya. Geoderma $11,275-285$.

Mosse, K.P.M., Patti, A.F., Christen, E.W., Cavagnaro, T.R., 2011. Review: Winery wastewater quality and treatment options in Australia. Australian Society of Viticulture and Oenology Inc., pp. 111-122.

Mulidzi, A.R., 2007. Winery wastewater treatment by constructed wetlands and the use of treated wastewater for cash crop production. Water Sci. Technol. 56, 103-109.

Murashkina, M.A., Southard, R.J., Pettygrove, G.S., 2007. Potassium fixation in San Joaquin Valley soils derived from granitic and nongranitic alluvium. Soil Sci. Soc. Am. J. 71, 125-132.

Nightingale, E.R., 1959. Phenomenological theory of ion solvation-effective radii of hydrated ions. J. Phys. Chem.-US 63, 1381-1387.

NRCS, 2011. In: Agriculture, U.S.D.o. (Ed.), Soil Survey. Natural Resources Conservation Service, USA

O’Geen, A.T., Pettygrove, S., Southard, R., Minoshima, H., Verdegaal, P.S., 2008. Soillandscape model helps predict potassium supply in vineyards. Calif. Agric. 62 195-201.

Oster, J.D., 1994. Irrigation with poor quality water. Agric. Water Manage. 25, 271-297.

Peacock, W., 2007. Potassium in Soils and Grapevine Nutrition [Online]., Available by UC Davis. 〈http://cetulare.ucdavis.edu/pubgrape/ng999.htm) (Verified 08/08/2012).

Quirk, J.P., 1986. Soil permeability in relation to sodicity and salinity. Philos. Trans, R. Soc. London, Ser. A 316, 297-317.

Quirk, J.P., 2001. The significance of the threshold and turbidity concentrations in relation to sodicity and microstructure. Aust. J. Soil Res. 39, 1185-1217.

Quirk, J.P., Schofield, R.K., 1955. The effect of electrolyte concentration on soil permeability. J. Soil Sci. 6, 163-178.

Ravina, I., Low, P.F., 1972. Relation between swelling, water properties and Bdimension in montmorillonite-water systems. Clays Clay Miner. 20, 109-\&.

Ravina, I., Markus, Z., 1975. Effect of high exchangeable potassium percentage on soil properties and plant-growth. Plant Soil 42, 661-672.

Rengasamy, P., 2002. Transient salinity and subsoil constraints to dryland farming in Australian sodic soils: an overview. Aust. J. Exp. Agric. 42, 351-361.

Rible, J.M., Quick, J., 1960. Method S-19.0., Cation Exchange Capacity. Tentative methods of analysis for diagnostic purposes. In: Experiment Service. Mimeographed Report. University of California Agricultural, Davis, CA.

Shainberg, I., Oster, J.D., Wood, J.D., 1980. Sodium-calcium exchange in montmorillonite and illite suspensions. Soil Sci. Soc. Am. J. 44, 960-964.

Shainberg, I., Singer, M.J., Janitzky, P., 1987. Effect of aluminum and ironoxides on hydraulic conductivity of sandy loam soil. Soil Sci. Soc. Am. J. 51, $1283-1287$

Shainberg, I., Singer, M.J., 1990. Agricultural Salinity Assessment and Management, Chapter 5 .

Sposito, G., 1989. The Chemistry of Soils. Oxford University Press, New York, Oxford, 019504615504613.

Sumner, M.E., 1993. Sodic soils-new perspectives. Aust. J. Soil Res. 31, 683-750.

Weber, E., Grattan, S.R., Hanson, B.R., Vivaldi, G.A., Meyer, R.D., Prichard, T.L. Schwankl, L.J., 2014. Recycled water causes no salinity or toxicity issues in Napa vineyards. Calif. Agric. 68, 59-67. 
Appendix A: $\Delta$ Cation Conc. Graphs for SAR 3 and

Changes in cation concentrations in soil column leachate for all SAR and PAR treatments.

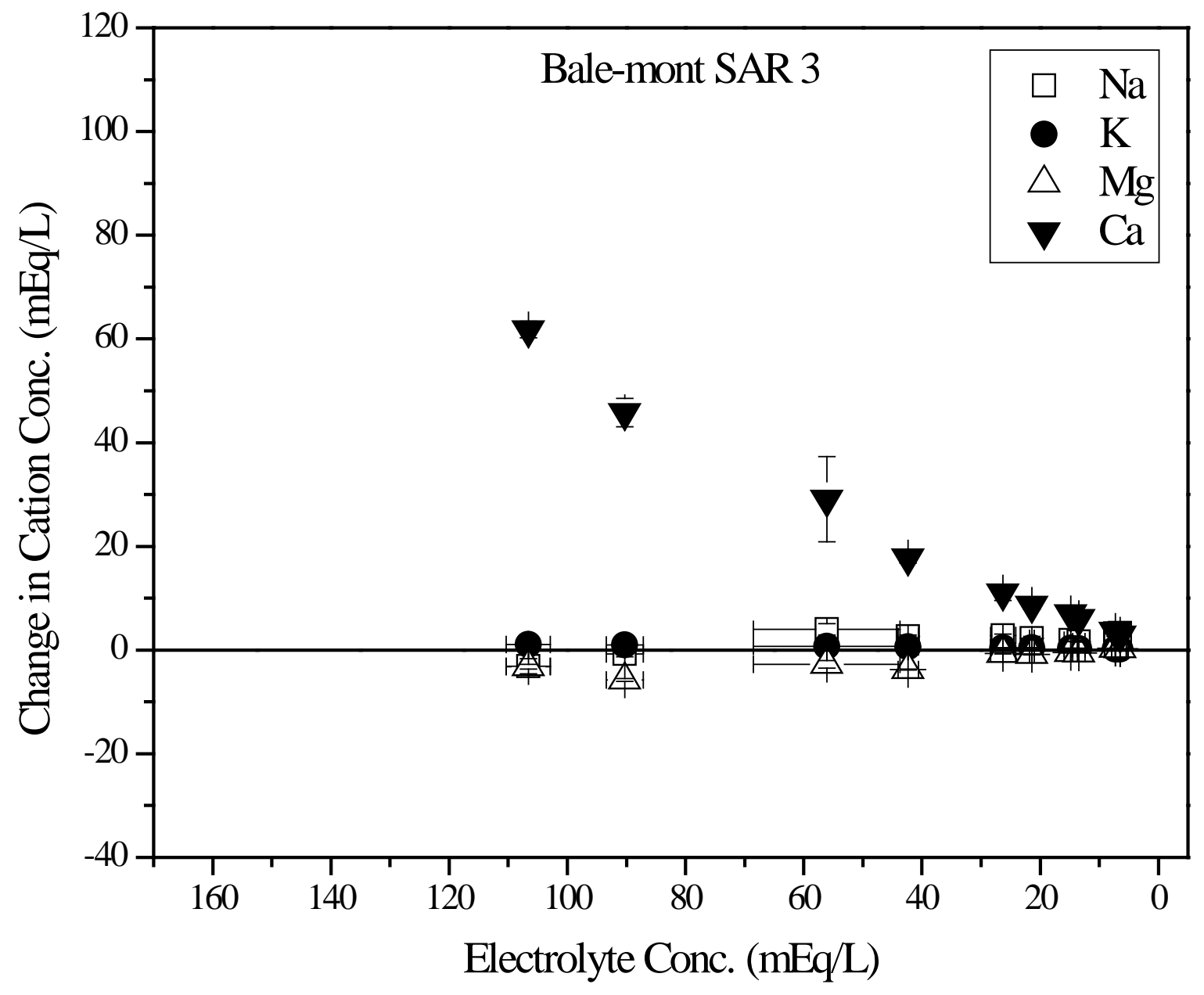

Figure A1. Change in cation concentration in Bale-mont leachate at SAR 3. Average of three column replicates with error bars representing one standard error of the mean. Points above the zero line indicate leaching and points below sorption. 


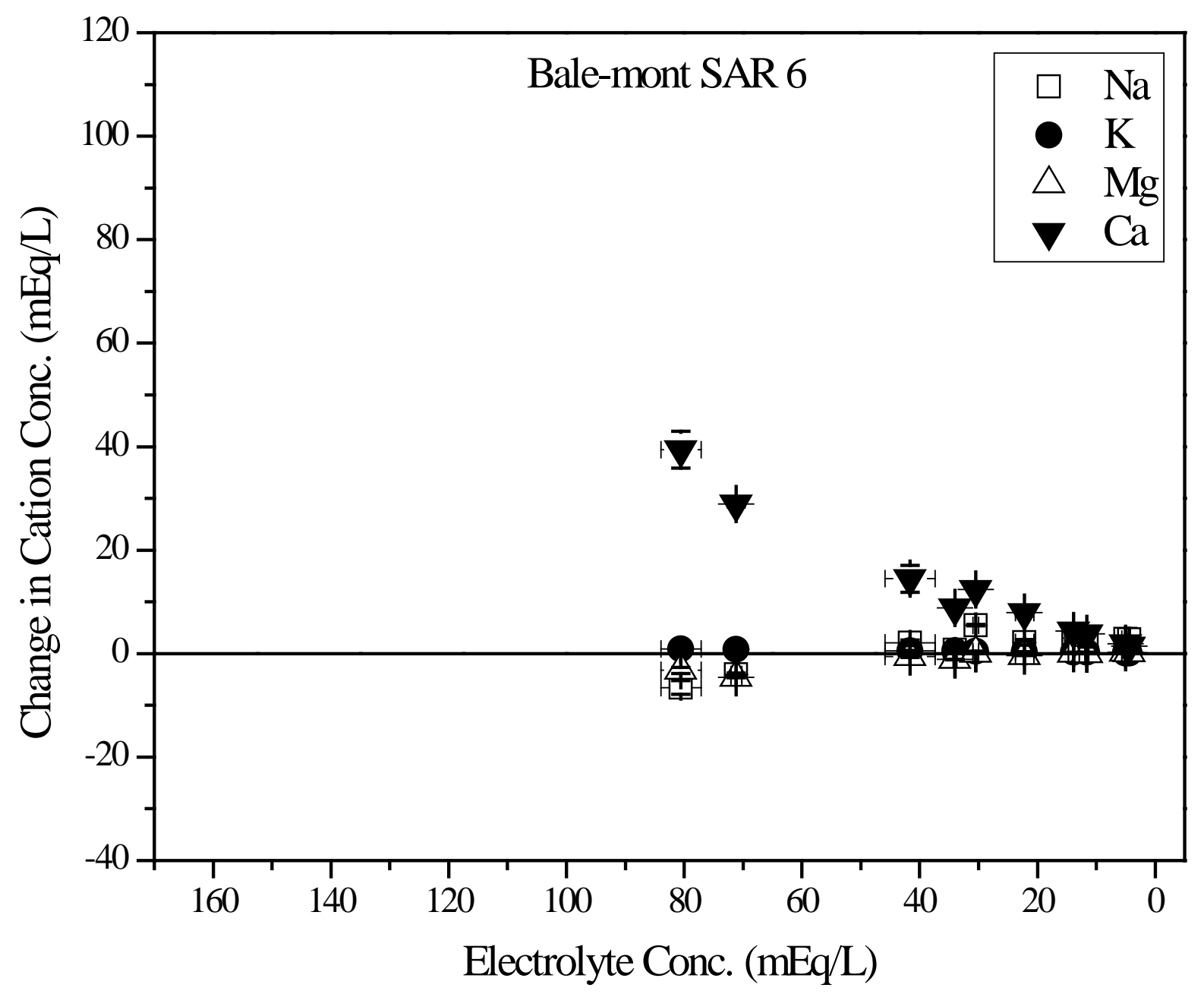

Figure A2. Change in cation concentration in Bale-mont leachate at SAR 6. Average of three column replicates with error bars representing one standard error of the mean. Points above the zero line indicate leaching and points below sorption. 


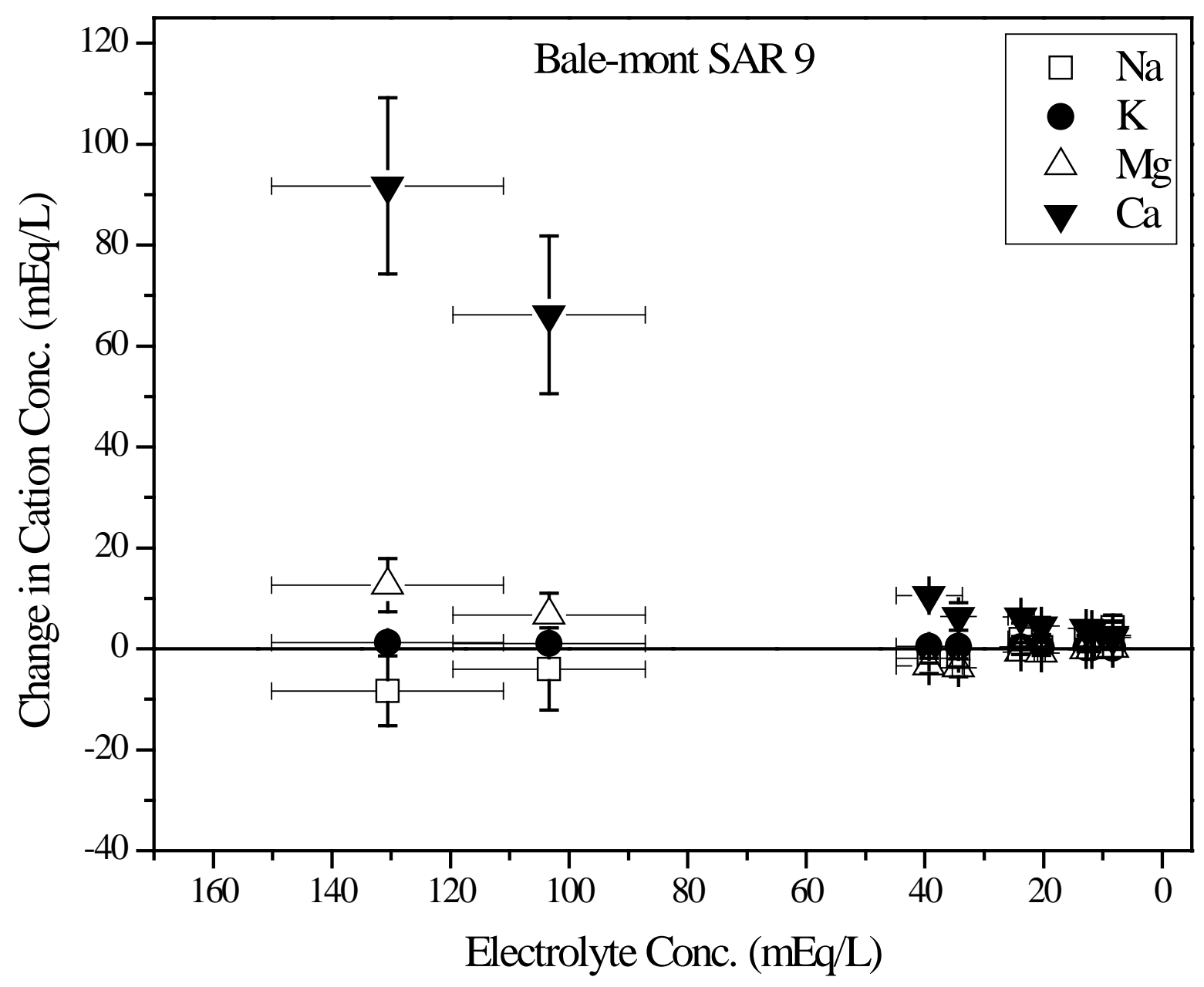

Figure A3. Change in cation concentration in Bale-mont leachate at SAR 9. Average of three column replicates with error bars representing one standard error of the mean. Points above the zero line indicate leaching and points below sorption. 


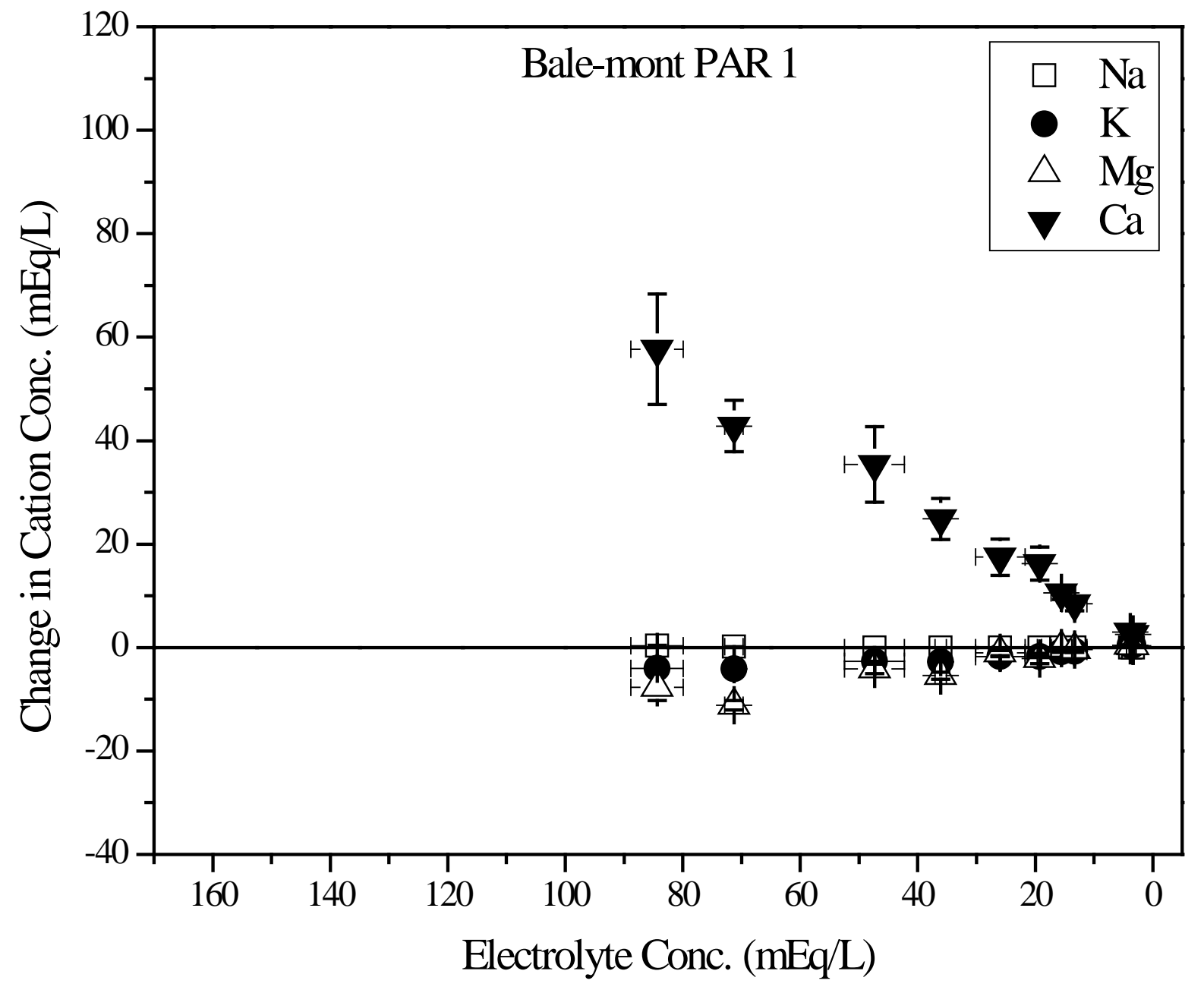

Figure A4. Change in cation concentration in Bale-mont leachate at PAR 1. Average of three column replicates with error bars representing one standard error of the mean. Points above the zero line indicate leaching and points below sorption. 


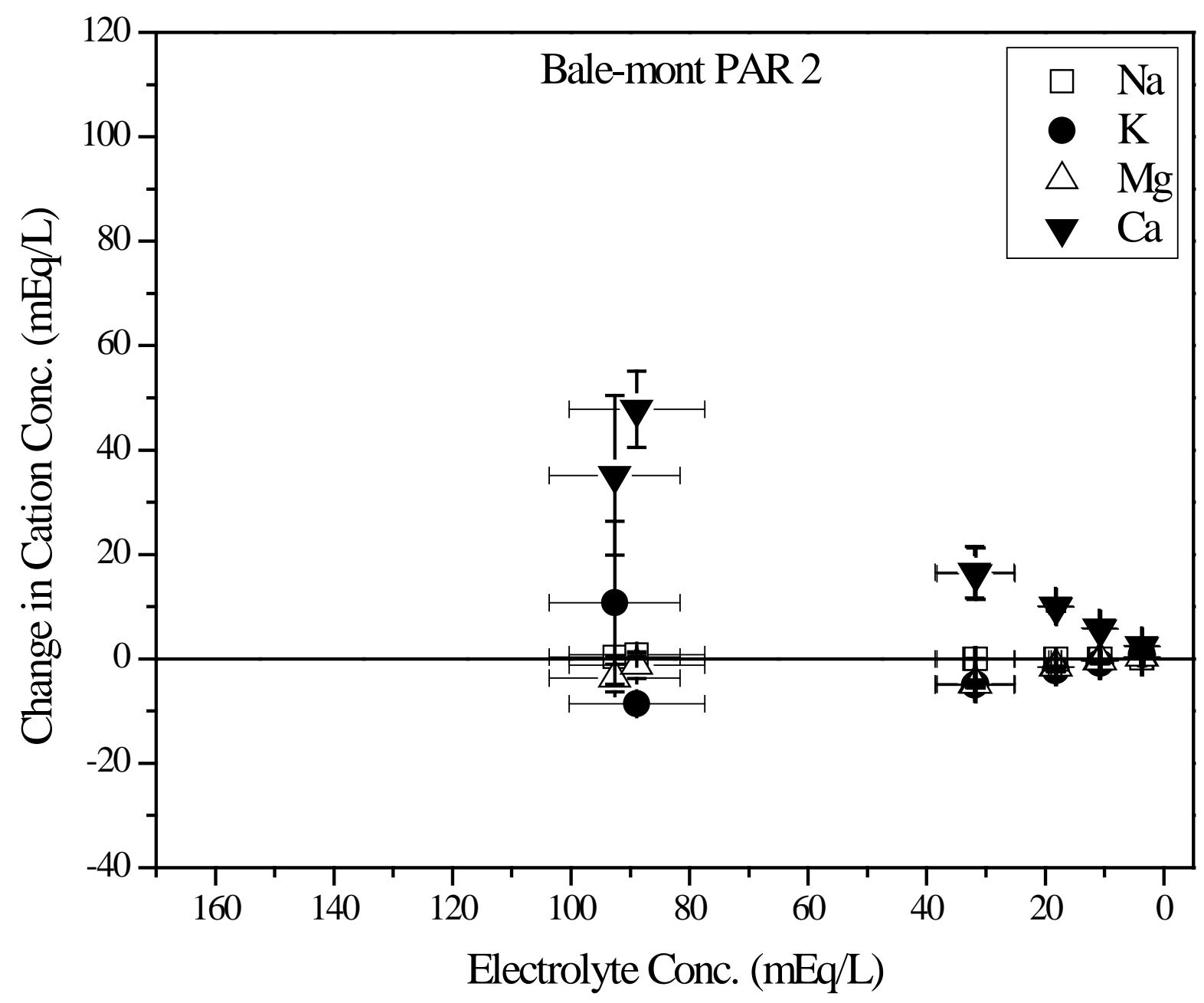

Figure A5. Change in cation concentration in Bale-mont leachate at PAR 2. Average of three column replicates with error bars representing one standard error of the mean. Points above the zero line indicate leaching and points below sorption. 


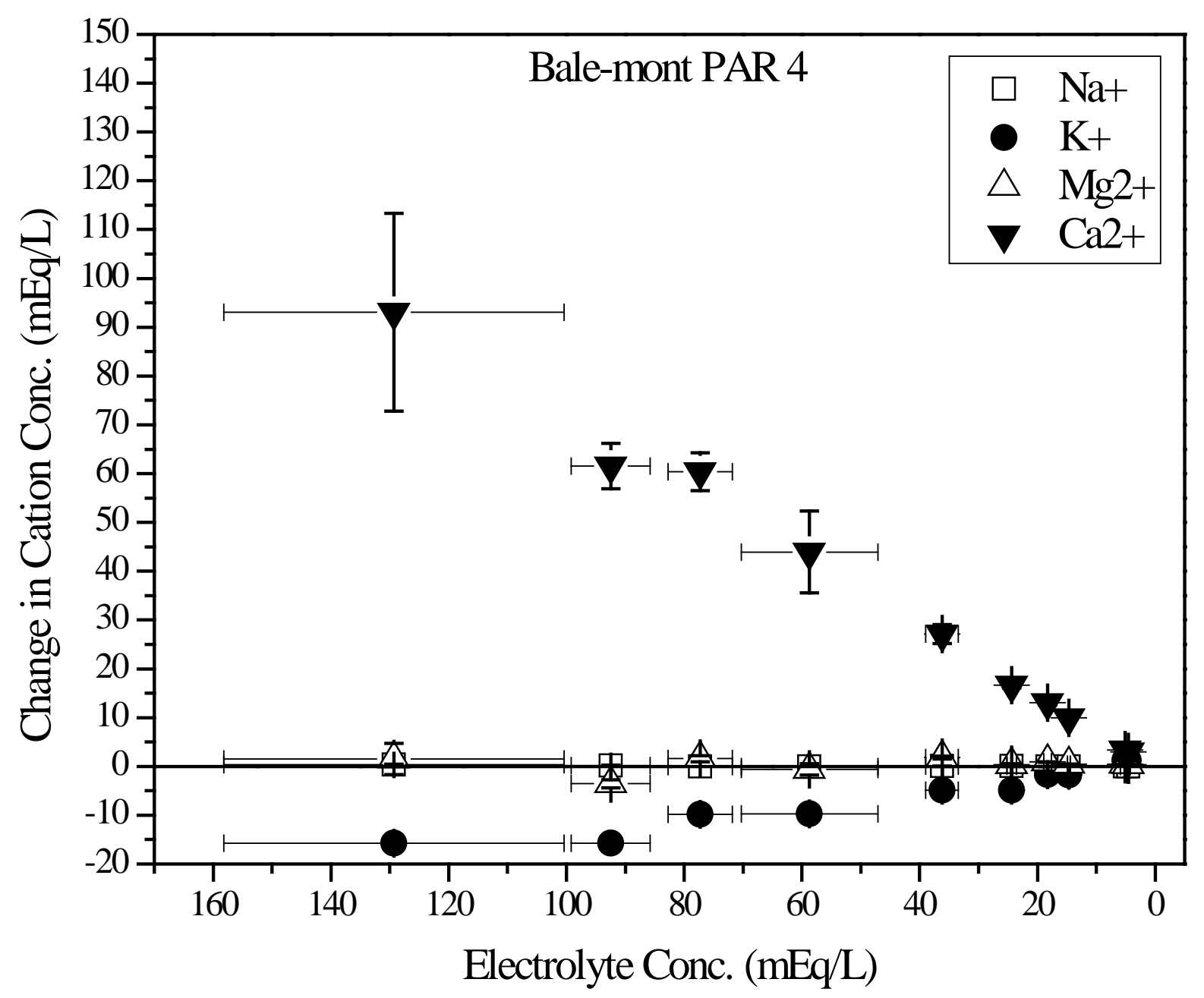

Figure A6. Change in cation concentration in Bale-mont leachate at PAR 4. Average of three column replicates with error bars representing one standard error of the mean. Points above the zero line indicate leaching and points below sorption. 


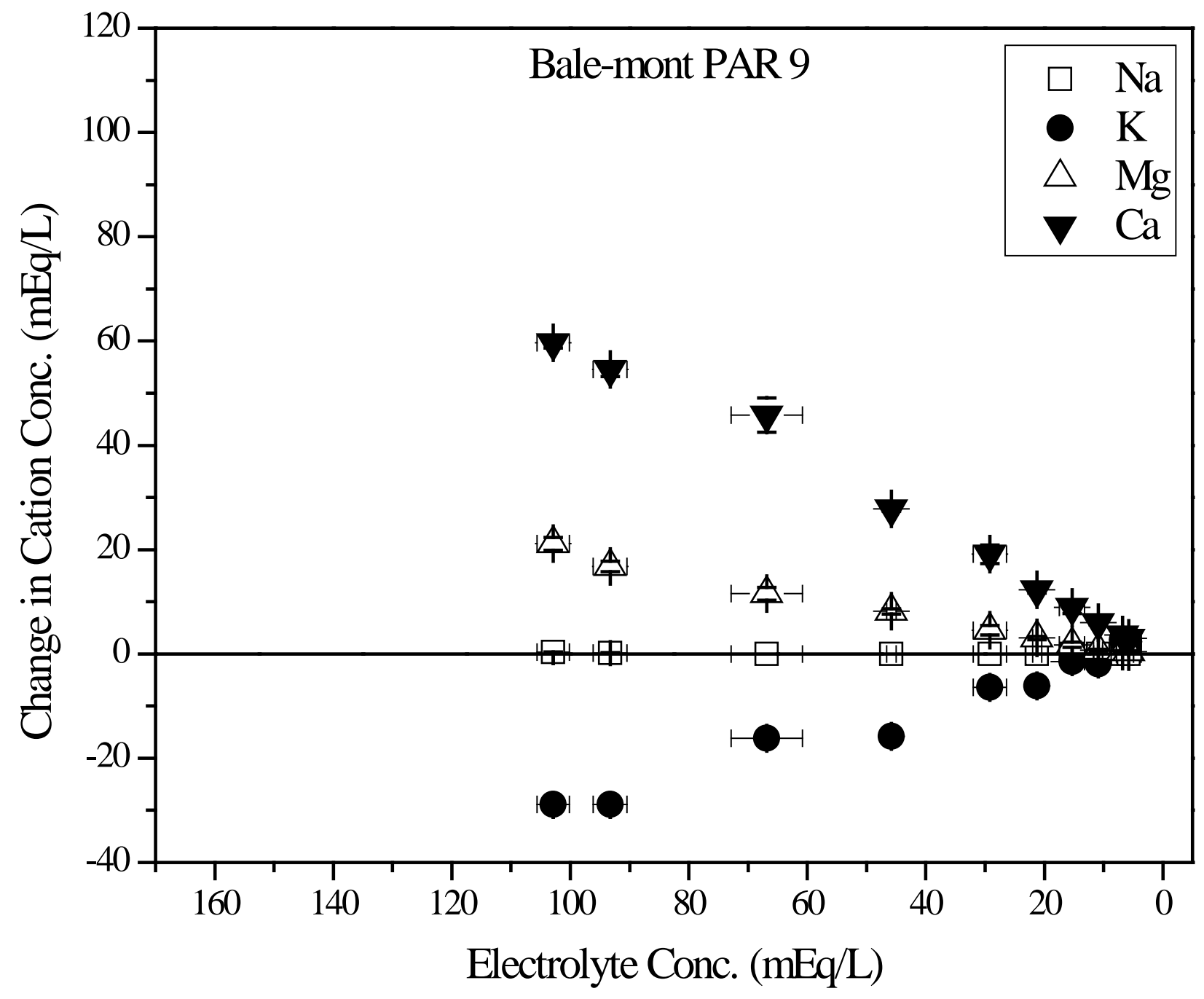

Figure A7. Change in cation concentration in Bale-mont leachate at PAR 9. Average of three column replicates with error bars representing one standard error of the mean. Points above the zero line indicate leaching and points below sorption. 


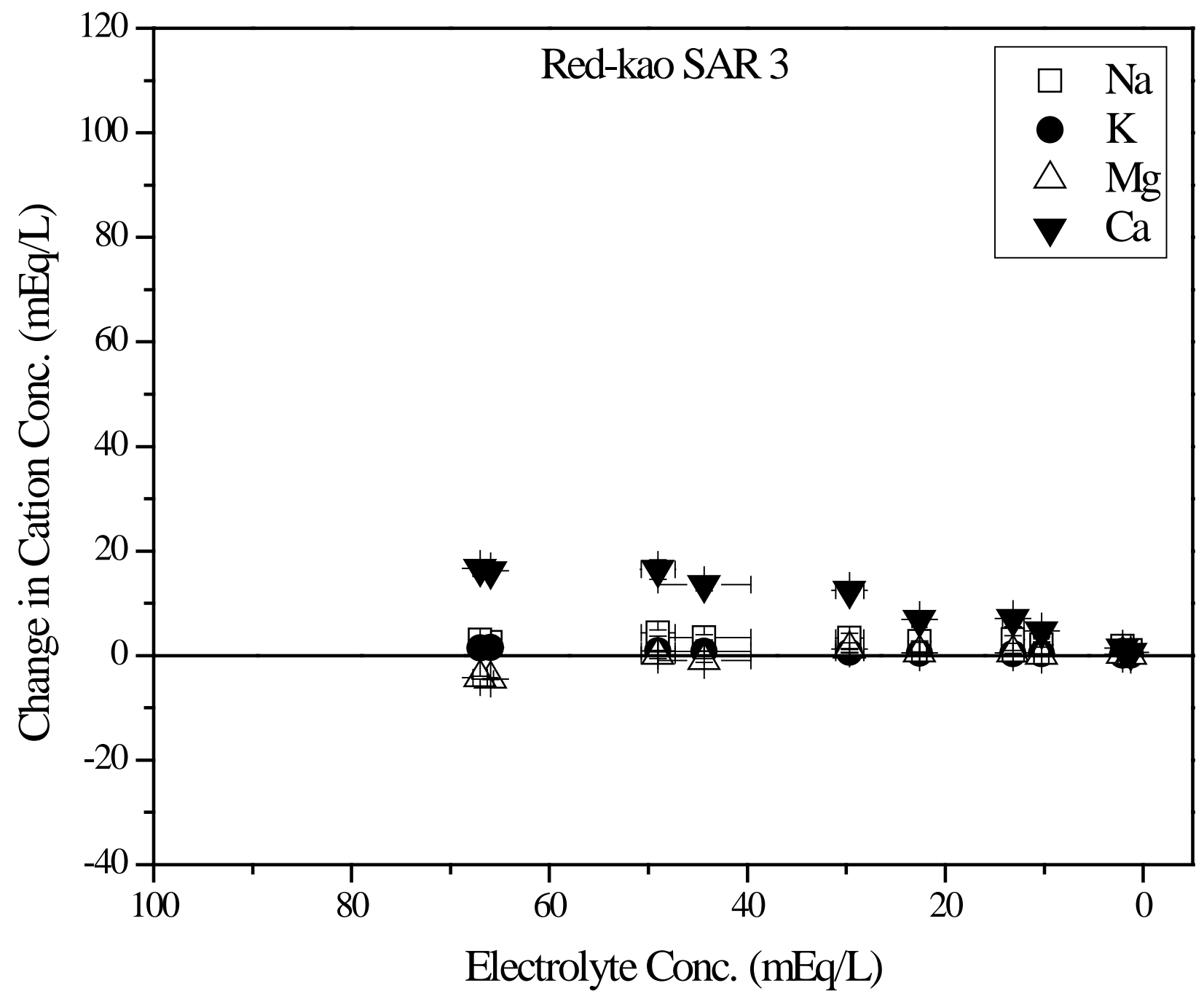

Figure A8. Change in cation concentration in Red-kao leachate at SAR 3. Average of three column replicates with error bars representing one standard error of the mean. Points above the zero line indicate leaching and points below sorption. 


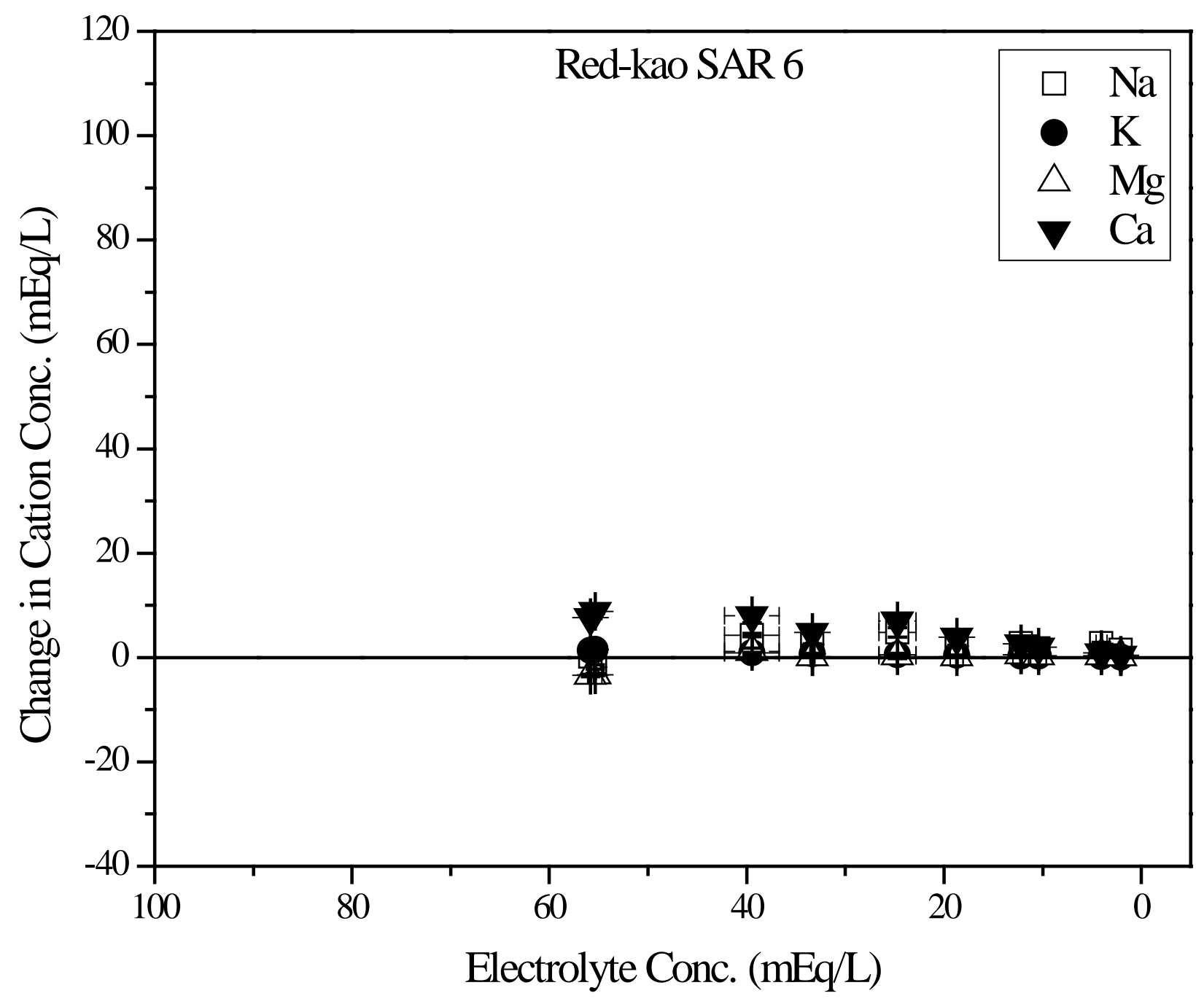

Figure A9. Change in cation concentration in Red-kao leachate at SAR 6. Average of three column replicates with error bars representing one standard error of the mean. Points above the zero line indicate leaching and points below sorption. 


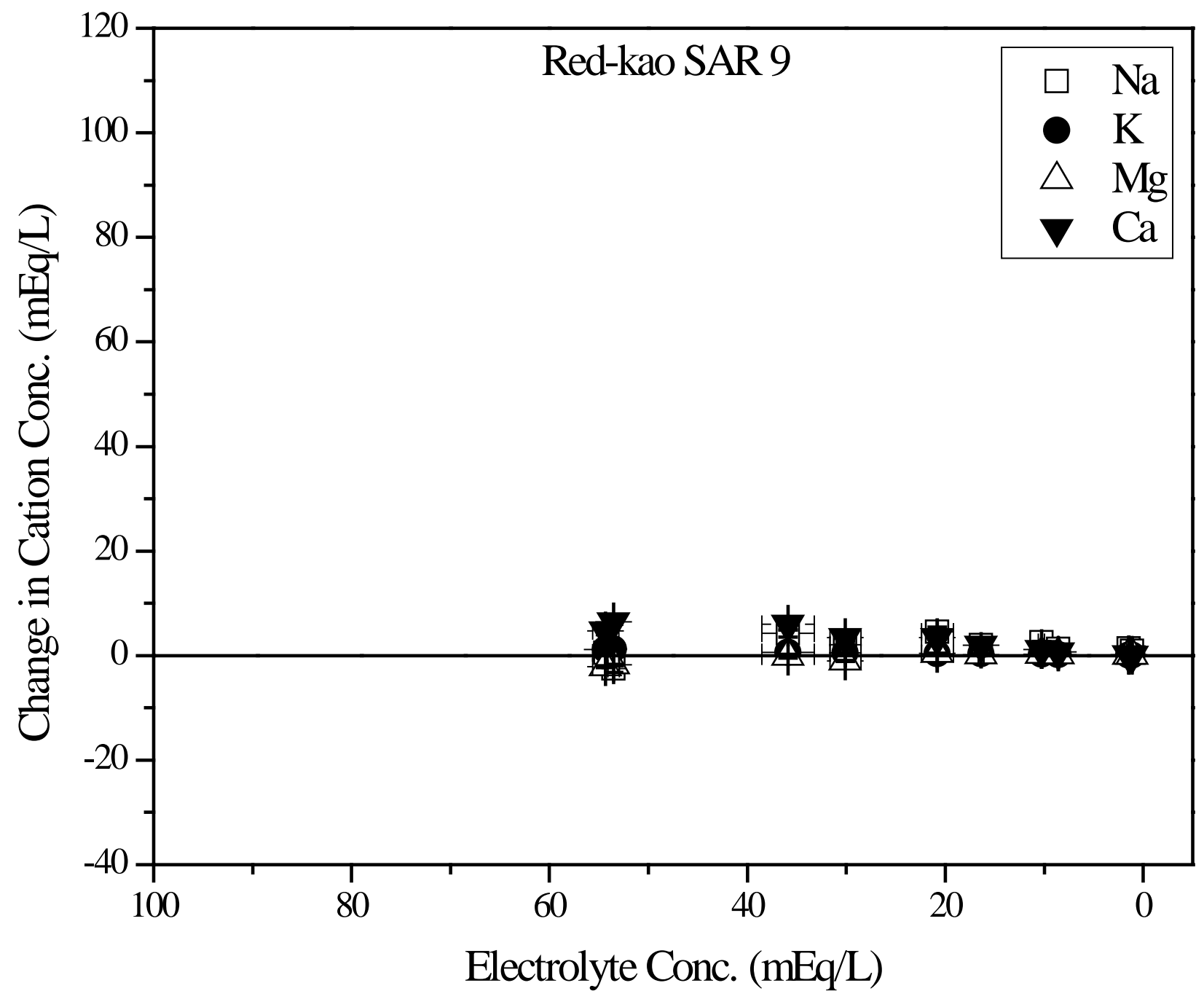

Figure A10. Change in cation concentration in Red-kao leachate at SAR 9. Average of three column replicates with error bars representing one standard error of the mean. Points above the zero line indicate leaching and points below sorption. 


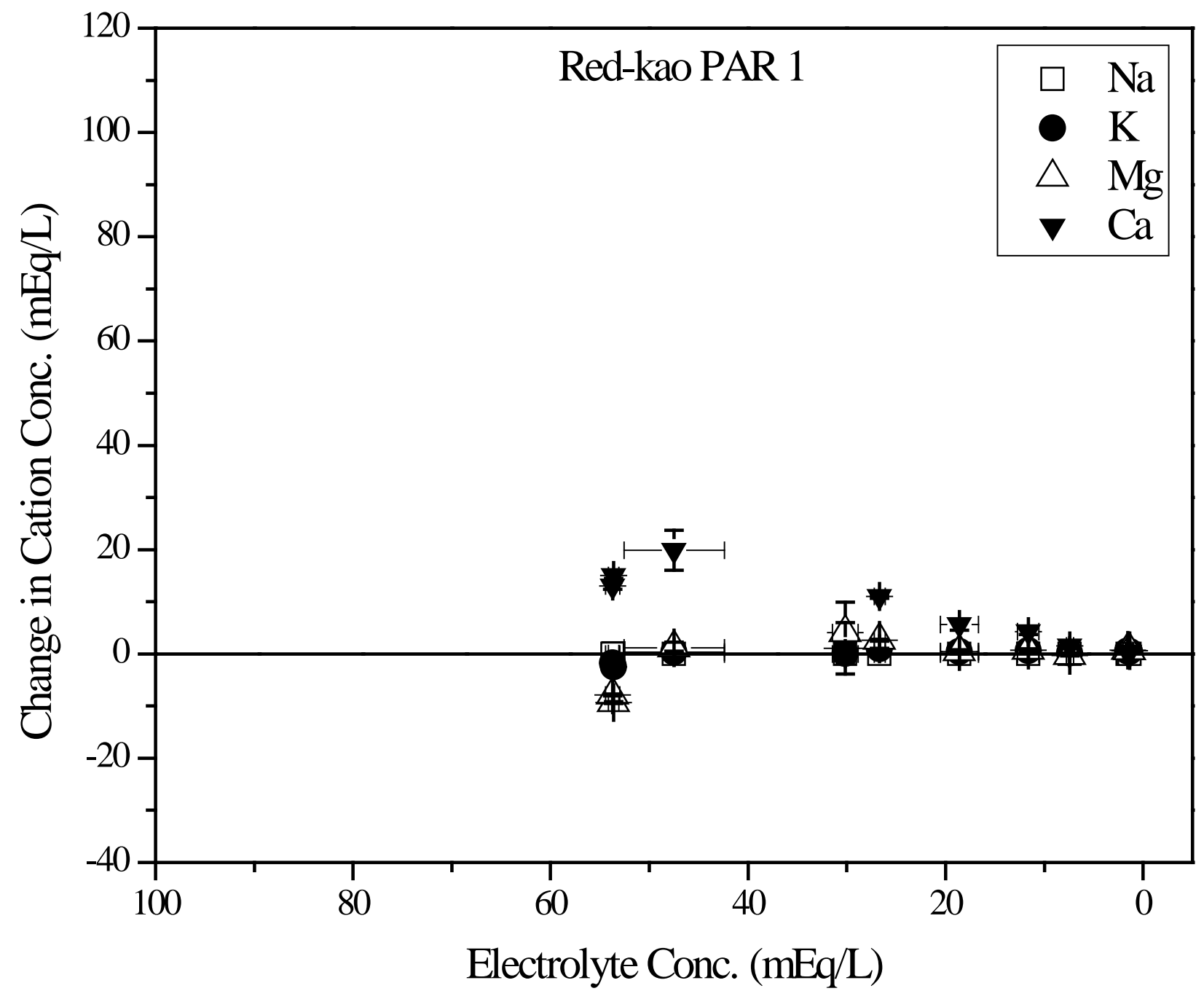

Figure A11. Change in cation concentration in Red-kao leachate at PAR 1. Average of three column replicates with error bars representing one standard error of the mean. Points above the zero line indicate leaching and points below sorption. 




Figure A12. Change in cation concentration in Red-kao leachate at PAR 2. Average of three column replicates with error bars representing one standard error of the mean. Points above the zero line indicate leaching and points below sorption. 


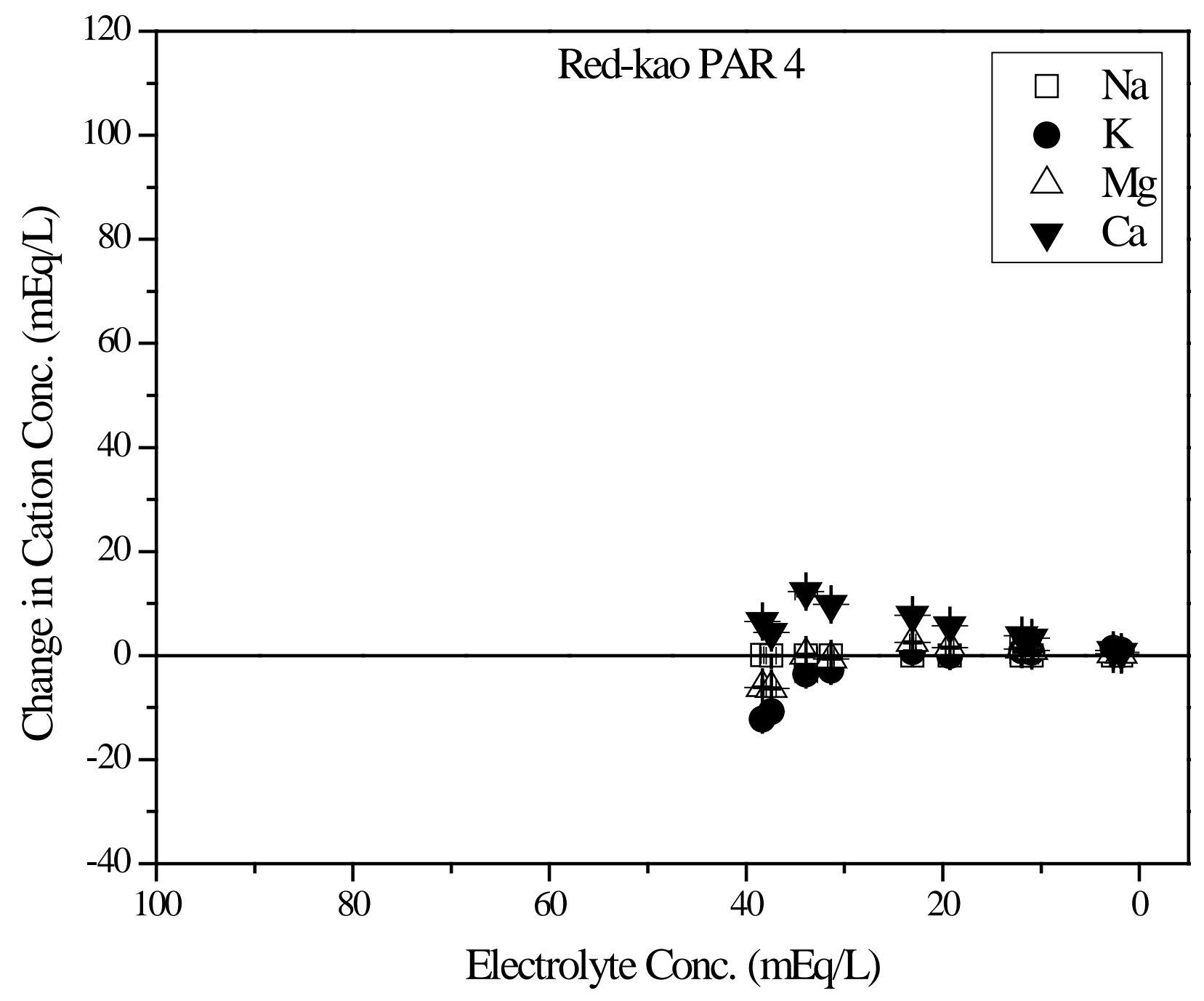

Figure A13. Change in cation concentration in Red-kao leachate at PAR 4. Average of three column replicates with error bars representing one standard error of the mean. Points above the zero line indicate leaching and points below sorption. 


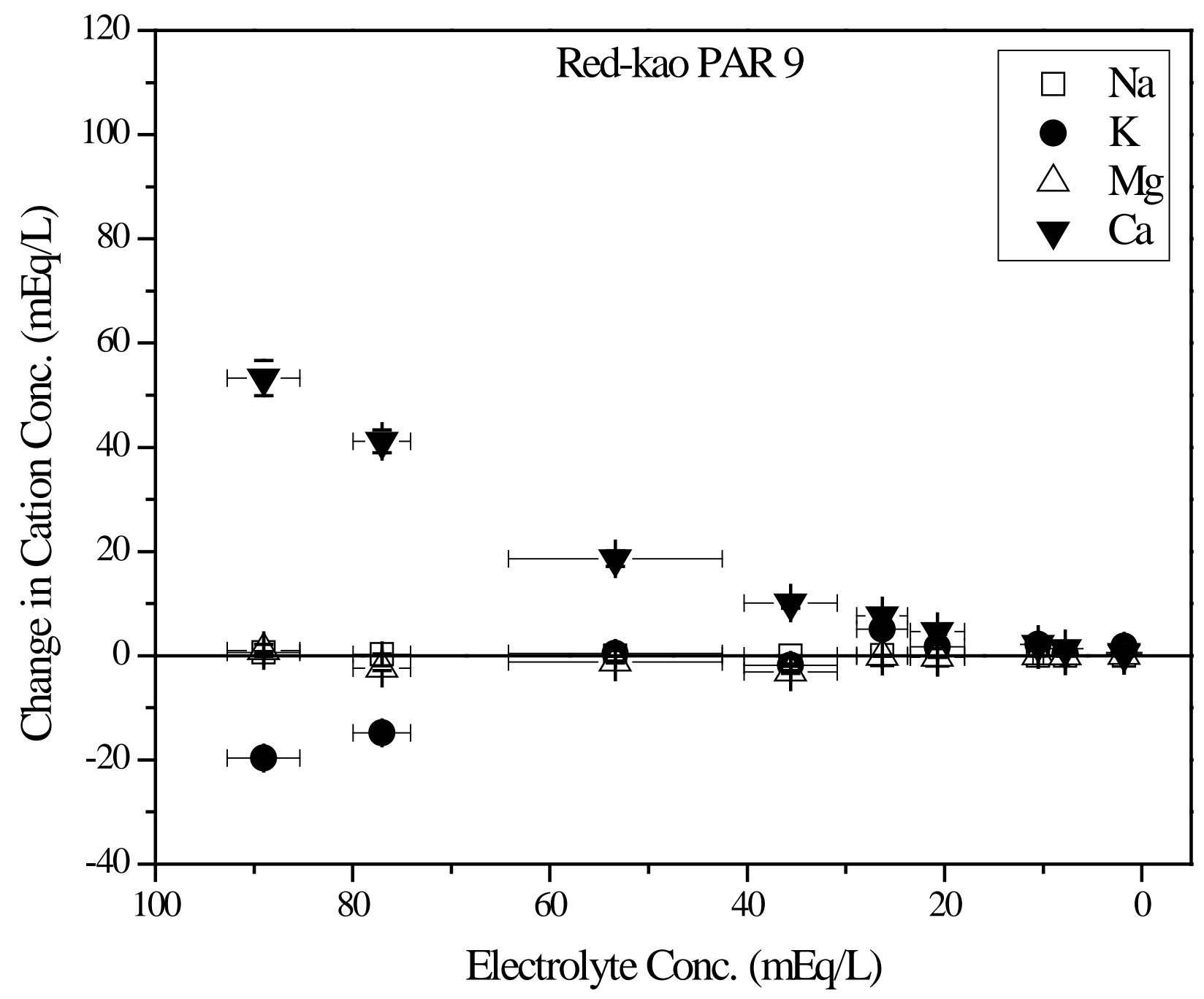

Figure A14. Change in cation concentration in Red-kao leachate at PAR 9. Average of three column replicates with error bars representing one standard error of the mean. Points above the zero line indicate leaching and points below sorption. 


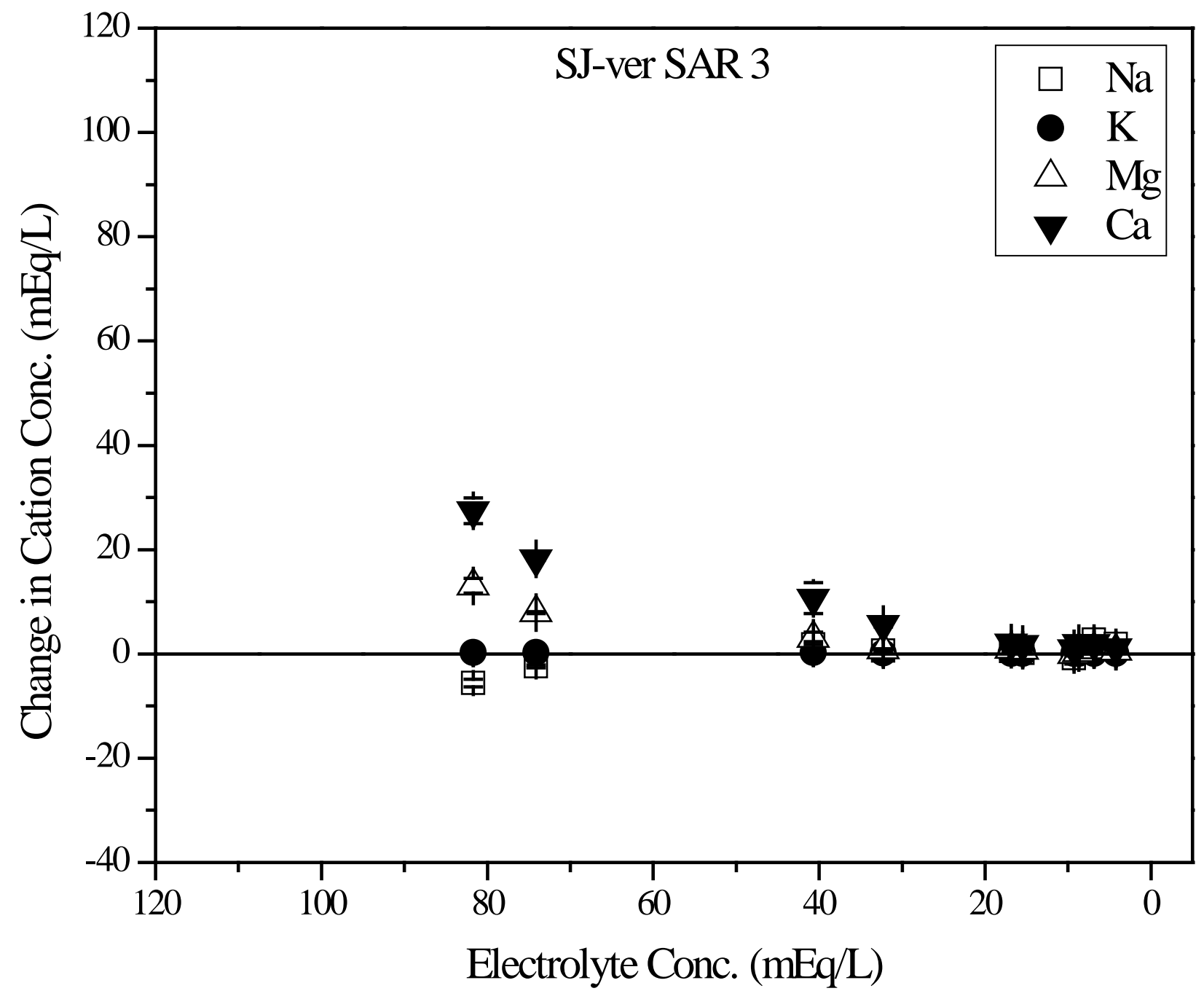

Figure A15. Change in cation concentration in SJ-ver leachate at SAR 3. Average of three column replicates with error bars representing one standard error of the mean. Points above the zero line indicate leaching and points below sorption. 


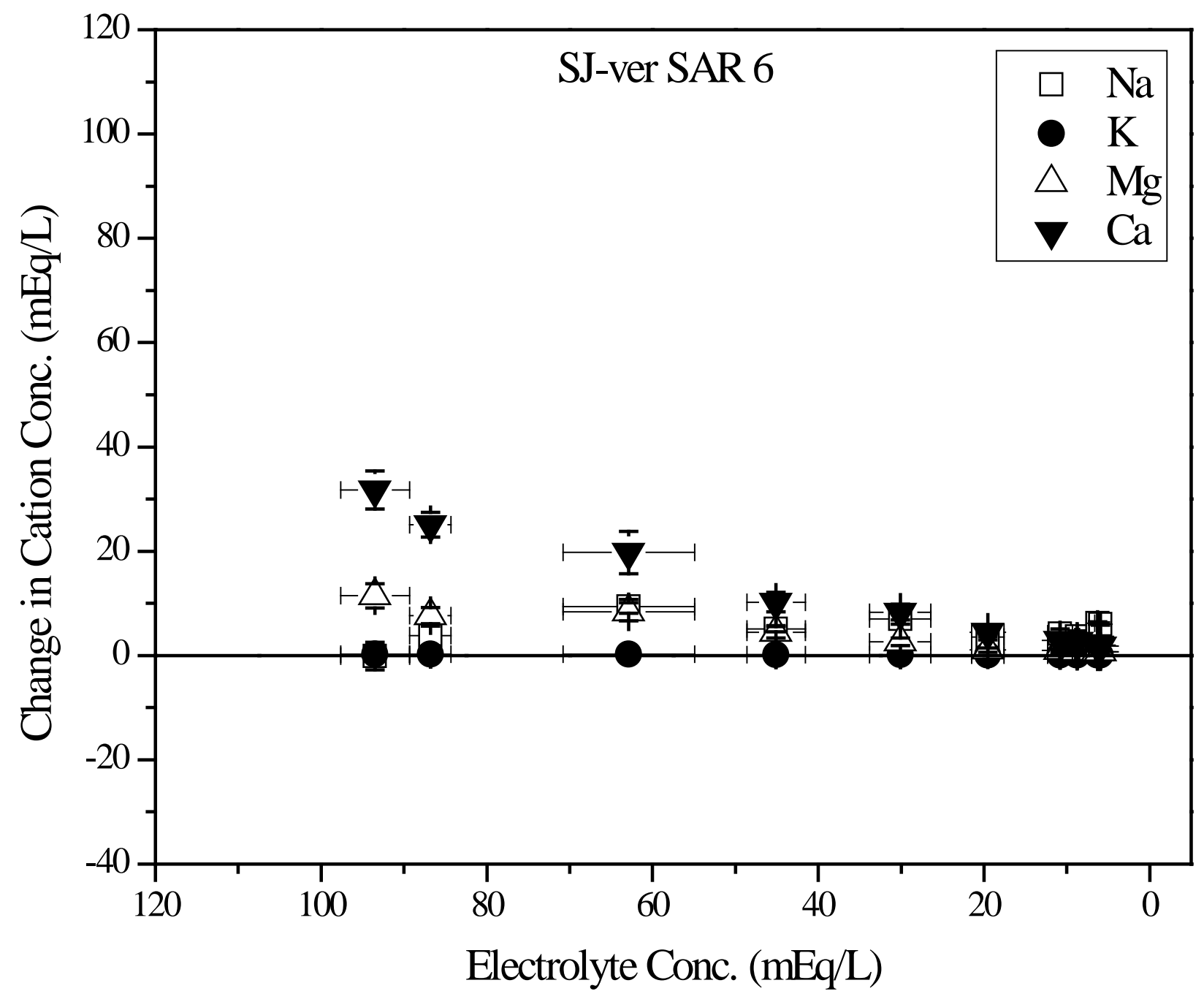

Figure A16. Change in cation concentration in SJ-ver leachate at SAR 6. Average of three column replicates with error bars representing one standard error of the mean. Points above the zero line indicate leaching and points below sorption. 


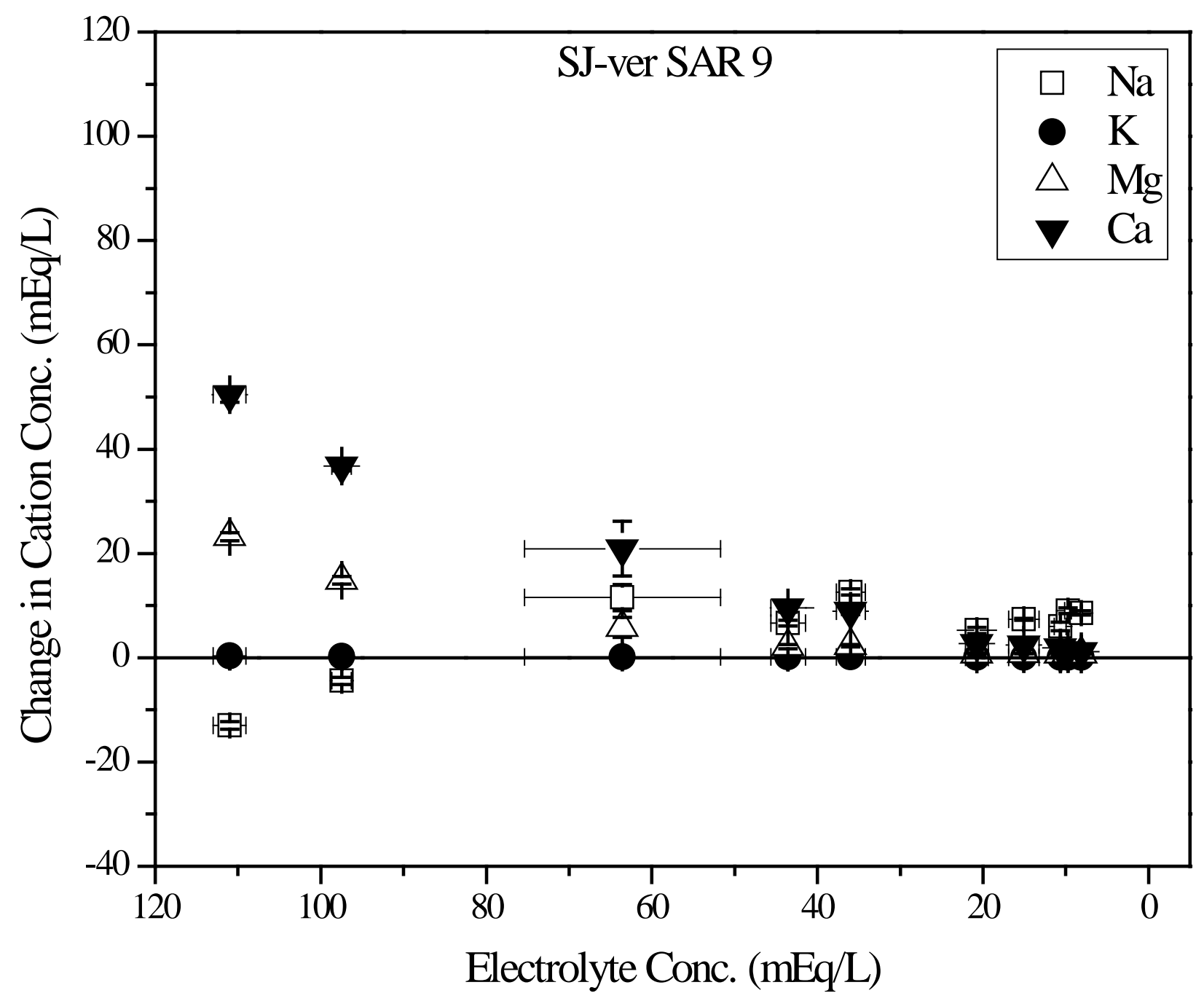

Figure A17. Change in cation concentration in SJ-ver leachate at SAR 9. Average of three column replicates with error bars representing one standard error of the mean. Points above the zero line indicate leaching and points below sorption. 


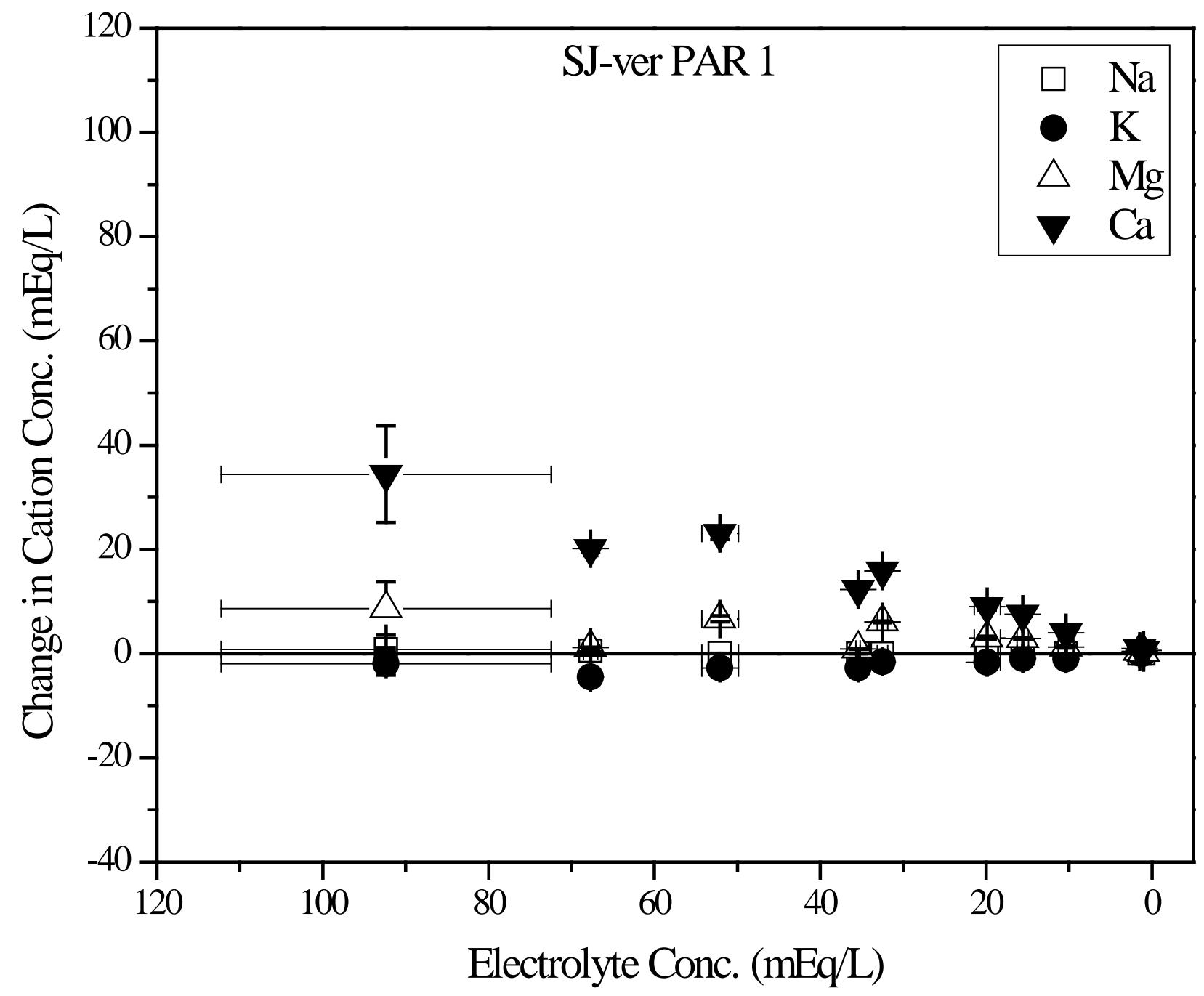

Figure A18. Change in cation concentration in SJ-ver leachate at PAR 1. Average of three column replicates with error bars representing one standard error of the mean. Points above the zero line indicate leaching and points below sorption. 


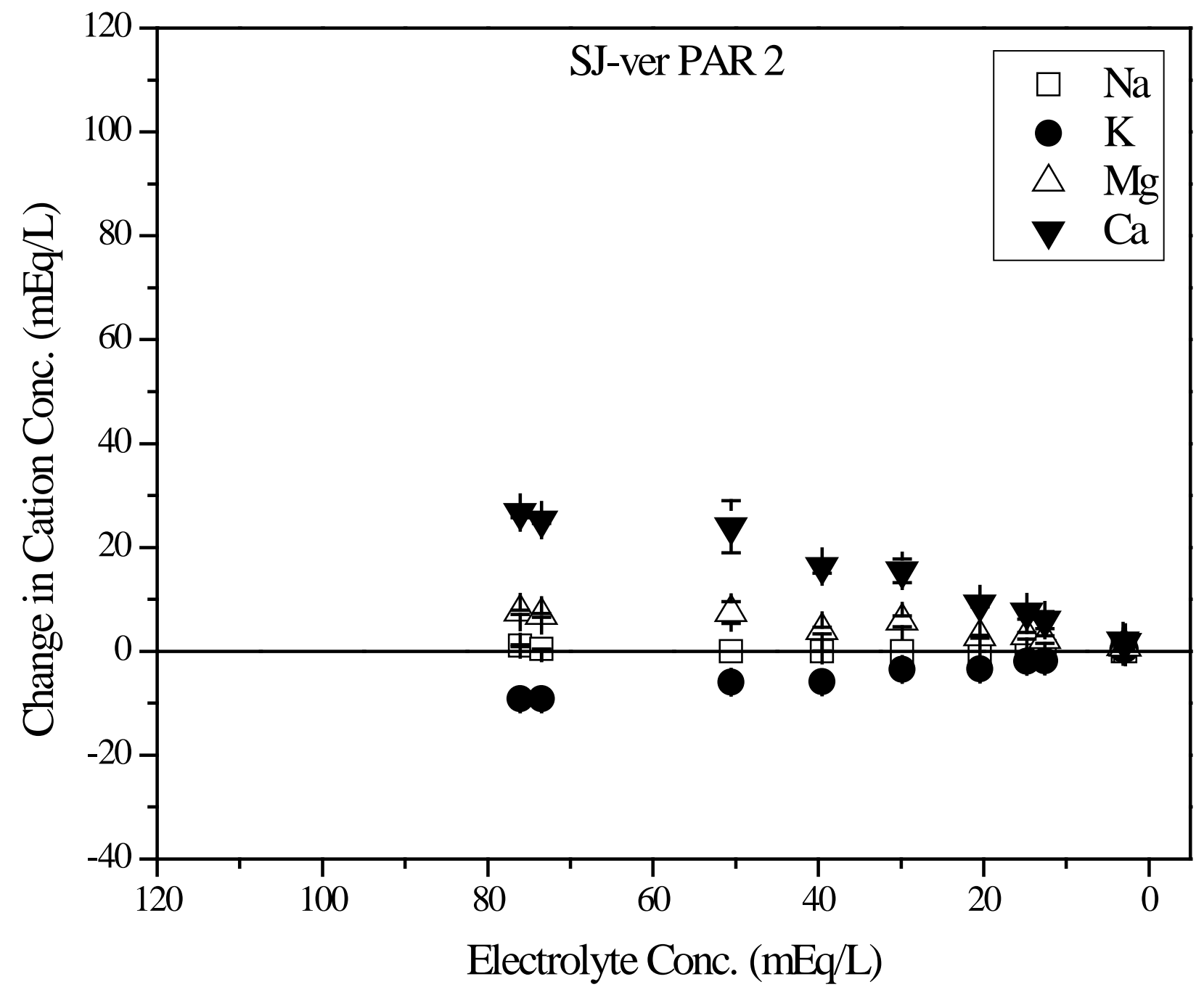

Figure A19. Change in cation concentration in SJ-ver leachate at PAR 2. Average of three column replicates with error bars representing one standard error of the mean. Points above the zero line indicate leaching and points below sorption. 


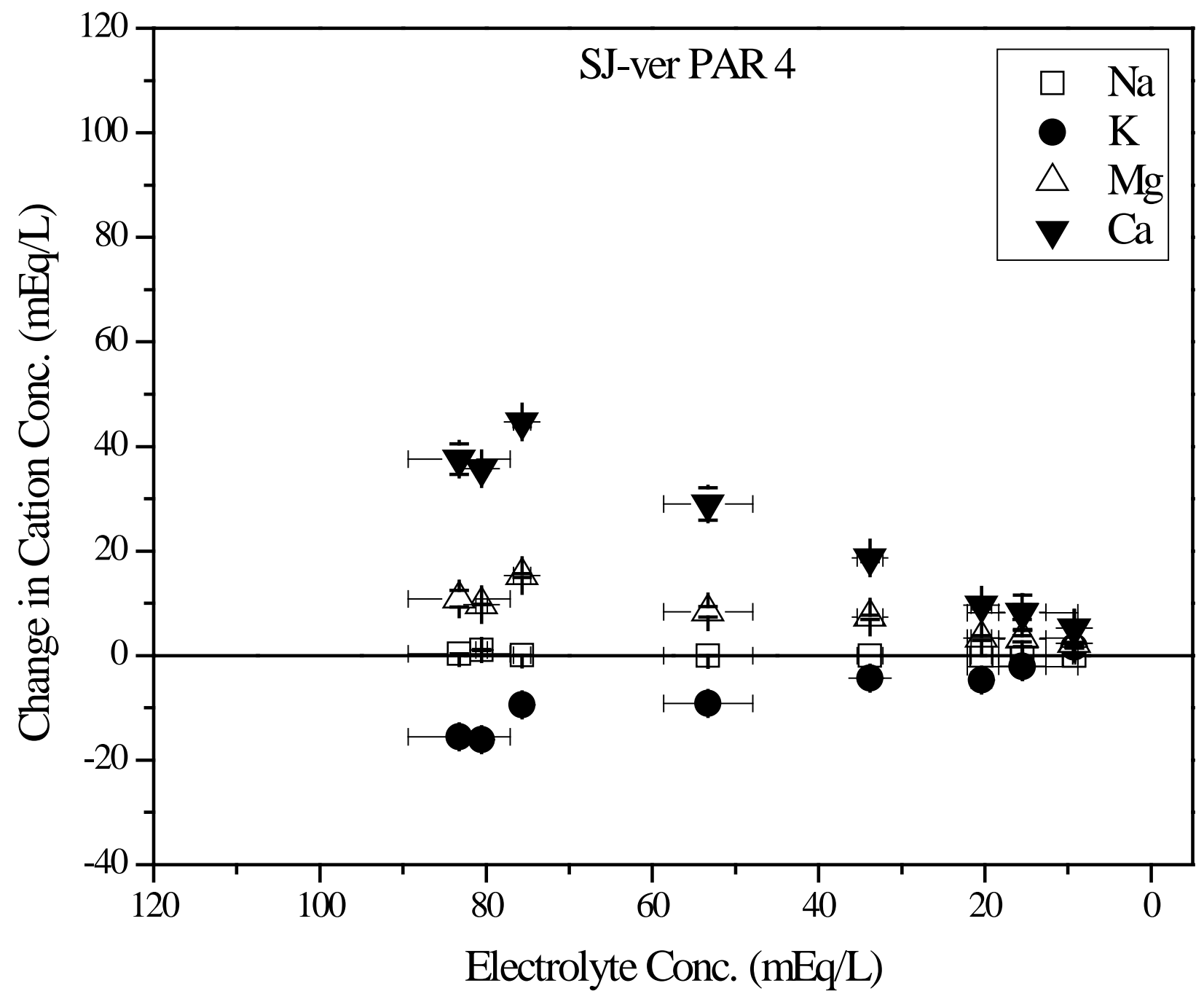

Figure A20. Change in cation concentration in SJ-ver leachate at PAR 4. Average of three column replicates with error bars representing one standard error of the mean. Points above the zero line indicate leaching and points below sorption. 




Figure A21. Change in cation concentration in SJ-ver leachate at PAR 9. Average of three column replicates with error bars representing one standard error of the mean. Points above the zero line indicate leaching and points below sorption. 